LVCENTVM, XI-XIII, 1992-94

\title{
CERÁMICA ROJA MONOCROMA ANATÓLICA EN EL POBLADO CALCOLÍTICO DE LES MORERES (CREVILLENTE, ALICANTE, ESPAÑA)
}

\author{
ALFREDO GONZÁLEZ PRATS* \\ ELISA RUIZ SEGURA* \\ JESÚS GIL FUENSANTA** \\ ROMUALDO SEVA ROMÁN* \\ *Universidad de Alicante \\ **Universidad Autónoma de Madrid
}

\begin{abstract}
En este artículo se valora el hallazgo en el poblado calcolítico de Les Moreres de una cerámica roja monocroma hecha a molde. Sus características tecnológicas delatan un origen alóctono, que los autores sitúan en la península anatólica, dentro del Bronce Antiguo (2700-2100 a.C.), barajándose tres áreas de elaboración posibles: Cilicia, la llanura de Konya y el occidente de Anatolia (Troya II-Demirci Höyük). La cerámica roja de Les Moreres permite probar la existencia de importaciones orientales en la Península Ibérica y, por tanto, de relaciones comerciales en el III milenio a.C. entre ambos extremos del Mediterráneo.

We consider moulded red monochrome ware found in the chalcolithic site at Les Moreres in this paper. Its technical features reveals a foreign origin from the Anatolian peninsula in Early Bronze Age (2700-2100 $\mathrm{BC})$ : Cilicia, Konya, Plain, Troya II-Demirci Höyük. Red ware from Les Moreres make us possible to show the fact of oriental imports into the iberian peninsula and therefore trade relationships in $3 \mathrm{rd}$. millenium $\mathrm{BC}$.
\end{abstract}

\section{PRIMERA PARTE}

El poblado de la Edad del Cobre de Les Moreres fue dado a conocer en Alcoy en 1984 con motivo del Coloquio sobre el Eneolítico en el País Valenciano (GONZALEZ PRATS, 1986).
Allí se ofrecía una primicia de los primeros resultados obtenidos en un sondeo a través del cual se detectó una vivienda y su contexto arqueológico, constituyendo un interesante hallazgo cerrado dado el 


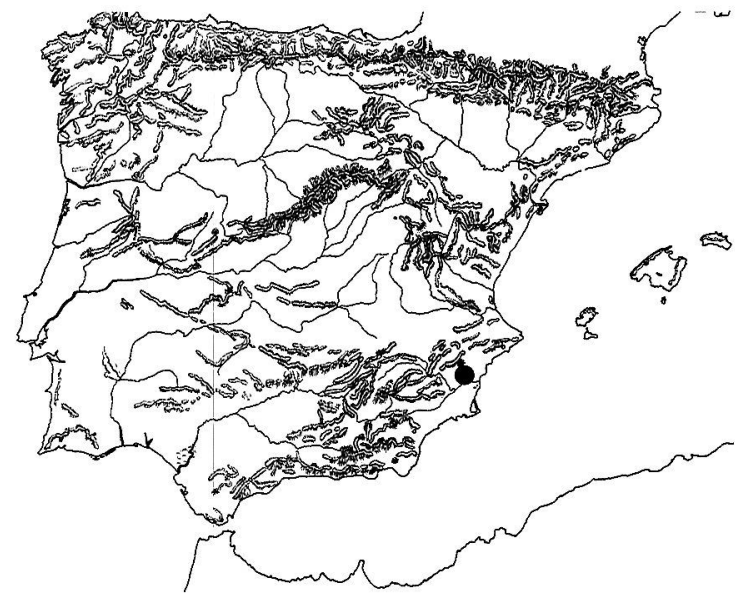

Fig.1.- Situación del poblado de Les Moreres.

carácter inalterado del contenido de dicha cabaña, que pereció incendiada.

Con anterioridad dimos a conocer el yacimiento de Les Moreres en el XVI Congreso Nacional de Arqueología celebrado en Murcia en 1982, en esta ocasión para presentar el nivel superior del mismo integrado por la necrópolis de cremación del Bronce Final (GONZALEZ PRATS, 1983).

La reactivación a partir de 1988 de las campañas de excavación en el doble yacimiento de Les Moreres-que constituye el Sector XI del Proyecto de La Peña Negra-nos ha permitido ampliar sustancialmente el registro arqueológico inicial y matizar la valoración que en su día realizamos.

Para el análisis del nivel correspondiente al poblado calcolítico han sido especialmente pródigas las campañas de 1988, 1989, 1991 y 1993, con cuyos registros podemos aproximarnos hoy a unã reconstrucción de la dinámica cultural y arquitectónica de las gentes que en la segunda mitad del III milenio a.C. habitaron el cerro de Les Moreres.

Así, en el plano arquitectónico, los datos que poseíamos inicialmente sobre el tipo de viviendas a base de paredes de barro con improntas de troncos han hallado su lugar en una secuencia cronológica interna.

A través del registro efectuado en los Cortes K.L.M.N.O.-6.7.8.9 hemos llegado a identificar tres fases sucesivas de construcción:

1. ${ }^{\text {a }}$ Fase. Representada por dos viviendas circulares halladas en los estratos IIa5-IIa6. Tienen zócalos de piedra con barro y arrojan unas dimensiones de unos 3-5 m. de diámetro.
2. ${ }^{a}$ Fase. Representada por una vivienda oval/circular de unos 3-5 m. de diámetro, con zócalos de piedras y barro. Corresponde al estrato IIa3.

$3 .^{a}$ Fase. Caracterizada por una gran vivienda ovalada con paredes delgadas de barro que cubren un núcleo de postes, cuyas improntas han quedado reflejadas en ellas. No presentan zócalo alguno de piedras. Su eje mayor se sitúa en 6-7 $\mathrm{m}$. Las paredes se conservan perfectamente al haber sido cocidas por la acción del incendio que destruyó el poblado.

De este modo, y en consonancia con el registro actual, parece existir una tendencia hacia un aumento en el tamaño de las viviendas, cambio que va parejo a la adopción de las estructuras más flexibles de la $3^{\text {a }}$ fase. Este cambio en la técnica de construcción podría venir obligado por fenómenos sísmicos - de hecho la vivienda del estrato IIa3 ( $2^{\mathrm{a}}$ fase) se derrumbó (estrato IIa4) sobre una de las viviendas de la $1^{\text {a }}$ fase- cuya acción se ha dejado sentir a través del tiempo en esta región, tan propicia para ello, del Sudeste peninsular.

Por lo que se refiere a la cultura material, el repertorio cerámico ofrece una tipología característica de los ambientes del Cobre Pleno y Final del Sur de Portugal y Andalucía. Así, se hallan presentes diversos tipos de cuencos, platos de borde engrosado y biselado por el interior, vasos de carenas media y baja y recipientes de paredes troncocónicas altas o bajas con fondos planos en alguno de los cuales se conservan las improntas de los capazos de esparto en donde fueron moldeados. A su lado, formas más habituales a lo largo de toda la Prehistoria como son los cuencos y las ollas. En la última fase del poblado se localizan varios ejemplos de cerámica incisa simbólica. De terracota utilizan soportes hiperboloides, pesas de telar oblongas con dos o cuatro perforaciones, cuernecillos o crecientes con doble perforación, amén de grandes vasijas de forma indeterminada.

La industria lítica incluye grandes placas de sílex tabular apuntadas con talla bifacial en los bordes denticulados, que podrían identificarse como alabardas; puntas de flecha de aletas y pedúnculo y de base cóncava, así como algunas hachas de piedra pulida.

En cuanto a los objetos de metal, cabe destacar la presencia de numerosos punzones, algún escoplo y un pequeño cuchillo de lengüeta. A este material hay que añadir dos puntas Palmela halladas en superficie.

Dos novedades deben de ser reseñadas a continuación. En primer lugar, la decidida aparición de 

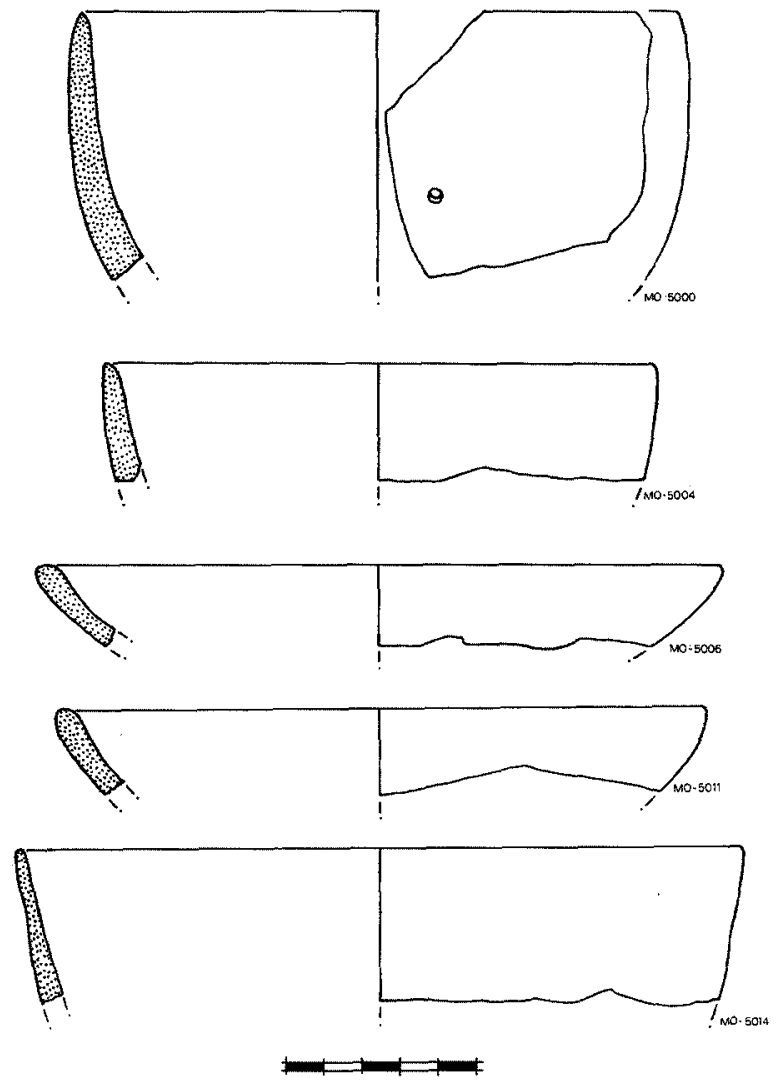

Fig 2. Formas de la cerámica roja monocroma.

cerámica campaniforme desde la campaña de 1990 nos obliga a desestimar el calificativo de precampaniforme con el que adjetivamos en su día el poblado de Les Moreres. Los datos de 1990 parecían situar esta especie cerámica en la fase de las viviendas con paredes de troncos y barro, pero el reciente registro de 1993 ha venido a demostrar la existencia de dicha cerámica a lo largo de la secuencia del poblado. Disponemos al menos de unas 35 vasijas —cuencos y vasos-que ofrecen decoración puntillada geométrica y, sobre todo, incisa.

En segundo lugar -el objeto en sí de este trabajo--, el hallazgo de un buen número de fragmentos pertenecientes a un tipo de cerámica monocroma roja cuyas características tecnológicas la apartan de las producciones habituales del Cobre peninsular y cuyo origen alóctono parece incuestionable, debiendo ser buscado en el Próximo Oriente mediterráneo, concretamente en la península anatólica.
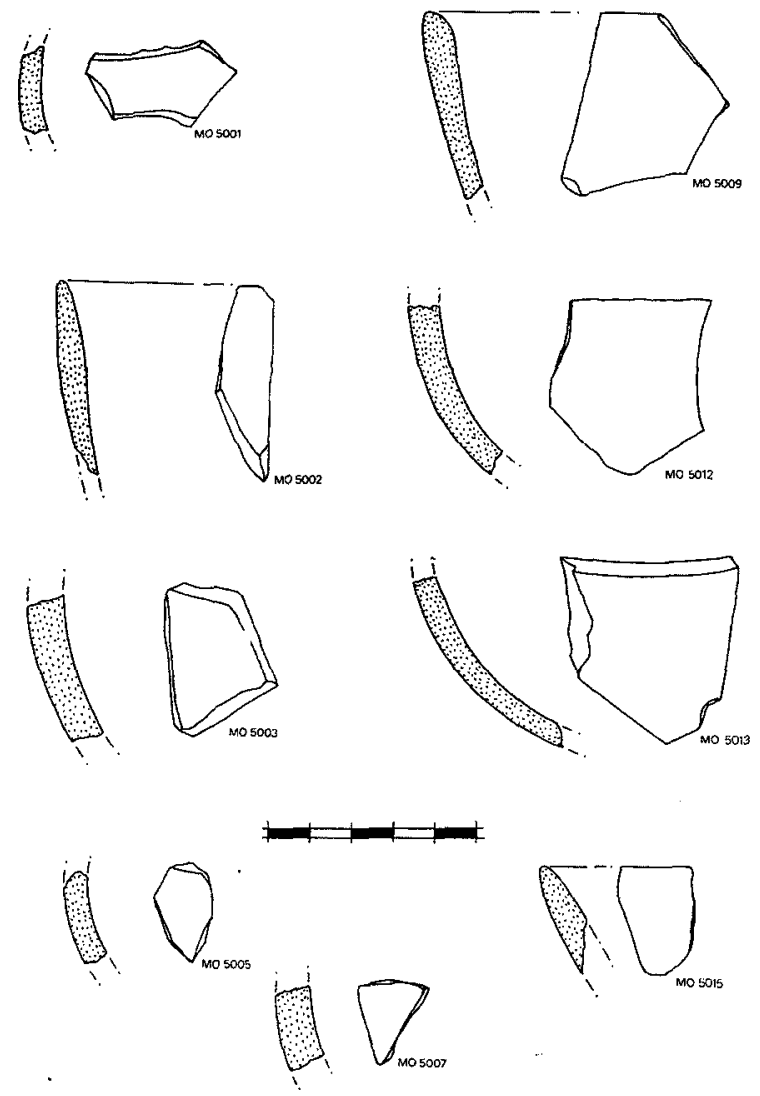

Fig. 3. Formas de la cerámica roja monocroma.

La excepcionalidad de semejante variedad cerámica, que fue considerada fabricada a torno en un principio por los directores de la excavación y por diversos especialistas nacionales y extranjeros consultados, condicionó que su presencia en el nivel del Cobre fuera cuestionada, habida cuenta de la existencia en el nivel superior de necrópolis de torno. Abierta la posibilidad de una intrusión para los primeros fragmentos - que, no obstante, aparecían en estratos inalterados del poblado inferior - uno de los objetivos prioritarios de la campaña de 1993 consistió en localizar la posición estratigráfica precisa de esta cerámica. El éxito ha sido definitivo y ha venido además asegurado por hallazgos de fragmentos de cerámica roja debajo del derrumbe de la vivienda de la segunda fase del poblado. Así, junto con la cerámica decorada campaniforme, hoy podemos asegurar que esta variedad aparece a lo largo de la secuencia de Les Moreres. Por otro lado, la forma que 

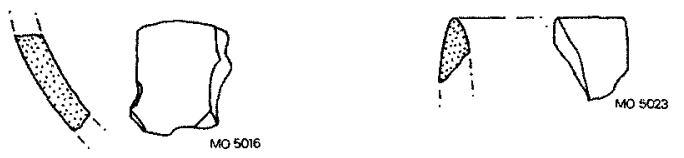

!
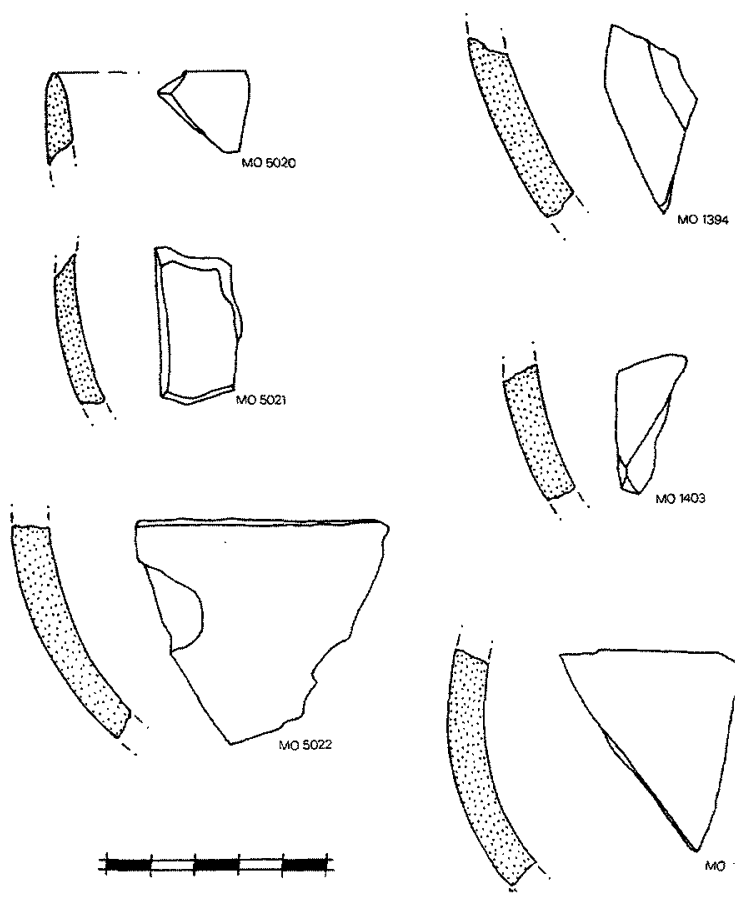

Fig. 4. Formas de la cerámica roja monocroma.

ofrecen estos vasos es ajena a la tipología cerámica de la necrópolis de cremación.

Inicialmente considerada fabricada a torno, la llamada de atención de R. Seva al analizar las pastas, nos obliga a definir estas vasijas como una fabricación a molde. Esta precisión invita, de paso, a cuestionar la elaboración a torno o a mano de muchos de los ejemplares anatólicos que mencionaremos y que así han sido considerados, ocultándose una manufacturación a molde detrás de tan conseguido producto.

Todas las piezas presentan un aspecto homogéneo, con arcillas idénticas y con los mismos componentes minerales. Se conforma así una producción de alta calidad, con superficies pulidas de color rojizo-anaranjado o rosáceo. Sus pastas son homogéneas o con un tenue núcleo gris claro. Algunas presentan un engobe rojizo y en la cara interna varios ejemplares ostentan un cuidadoso espatulado. Las inclusiones minerales que actúan como desgrasante incluyen un muy fino componente
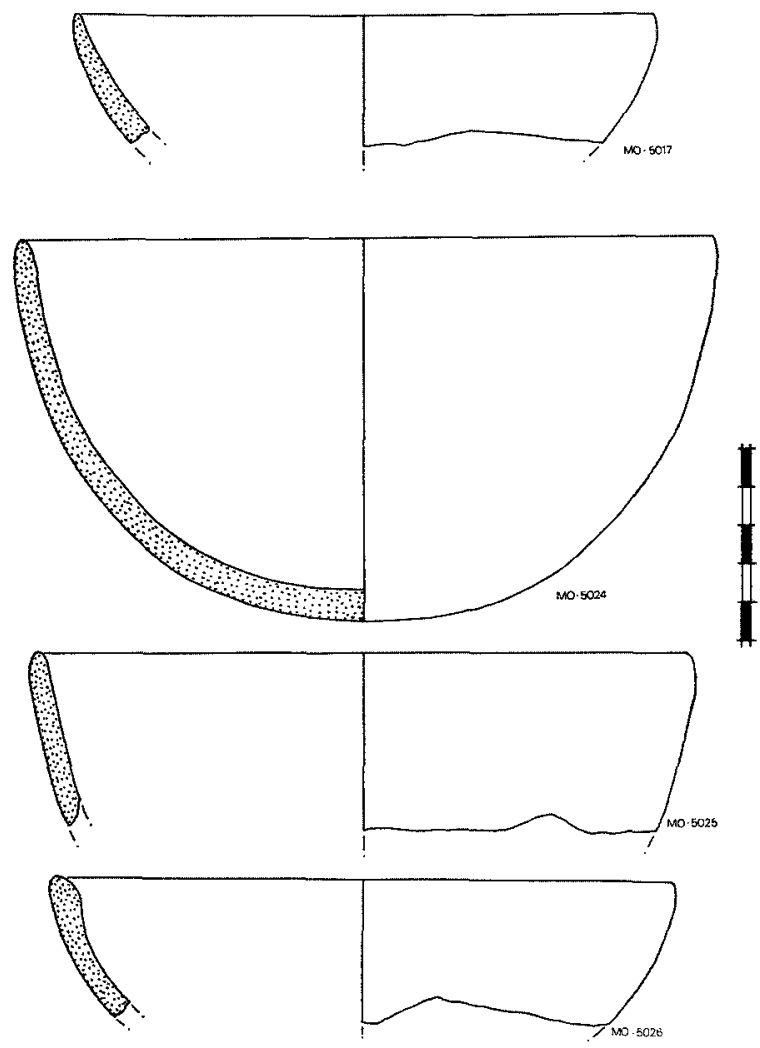

Fig. 5. Formas de la cerámica roja monocroma.

micáceo al lado de otros gránulos mayores de óxidos de hierro.

\section{INVENTARIO DE LAS PIEZAS}

MO-5000. Fragmento de un cuenco de cerámica rosácea. Hecho a molde. Superficie externa erosionada, en origen pulida. Superficie interna con notorio espatulado. Pasta homogénea rosácea-gris con desgrasante micáceo fino y otros de mayor tamaño. Posee agujero de lañado. Hallado en superficie.

MO-5001. Fragmento de cerámica de superficie rojizo-anaranjada. Hecho a molde. Pasta roja homogénea con muy fino desgrasante micáceo. Superficies pulidas. Hallado en el estrato Ila3 del Corte 07.

MO-5002. Fragmento de borde de un cuenco hecho a molde. Superficie rojizo-anaranjada con la pasta del mismo color, homogénea con fino desgrasante micáceo y gránulos mayores de óxido de hierro. Superficies pulidas. Hallado en el estrato IIa3 del Corte 07.

MO-5003. Fragmento de cerámica hecha a molde. Superficie rojizo-rosáceo. Pasta con núcleo gris claro con abundante desgrasante micáceo muy fino e inclusiones mayores de 6 xidos de hierro. Superficie externa pulida e interna con huellas de espatulado. Hallado en el estrato IIa3-IIb del Corte M8. 

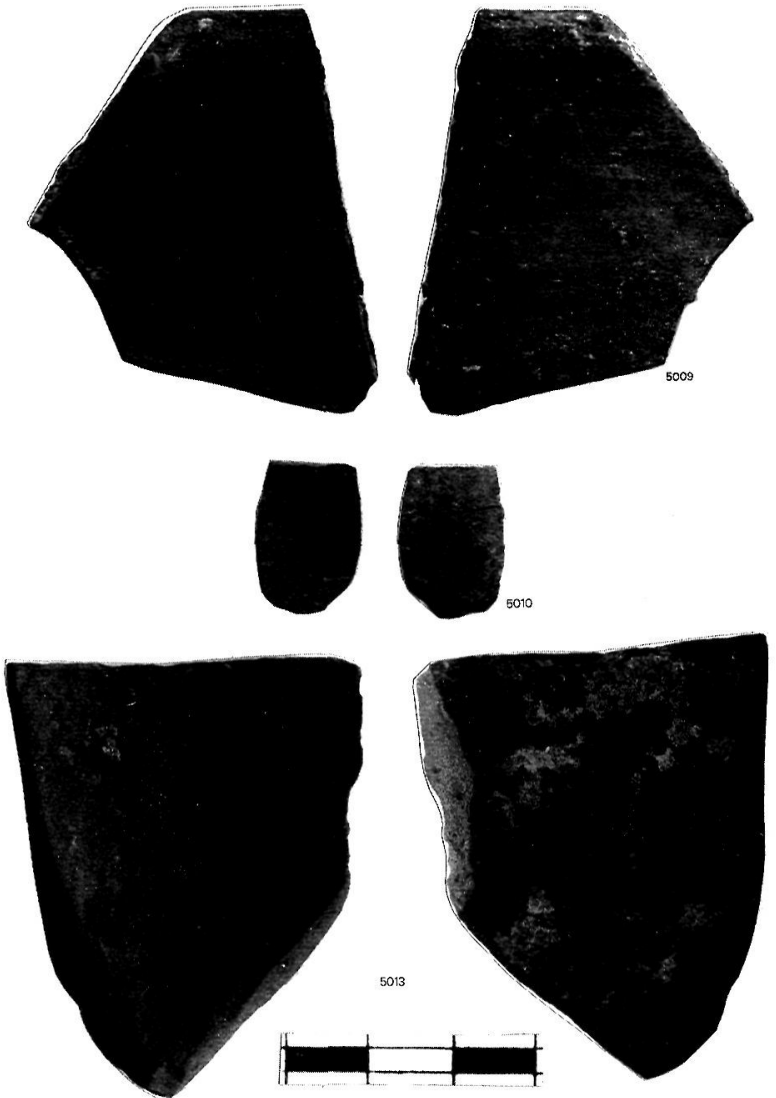

Lám. I.- Cerámica roja monocroma de Les Moreres.

MO-5004. Fragmento de borde de un cuenco hecho a molde. Cerámica de color rojo ladrillo con la pasta homogénea. Superficies pulidas y restos de engobe. Fino desgrasante micáceo. Hallado en el estrato IIa3-IIb del Corte M8. MO-5005. Fragmento de cerámica anaranjada hecha a molde. Pasta homogénea con fino desgrasante micáceo. Superficies pulidas. Hallado en el estrato Ila3 del Corte M8. MO-5006. Fragmento de borde de un cuenco hecho a molde. Cerámica de color rosáceo-rojizo con la pasta homogénea. Desgrasante micáceo muy fino y gránulos de óxidos de hierro. Superficies pulidas. Hallado en el estrato 1 Ia2 del Corte M8.

MO-5007. Fragmento de cerámica hecha a molde Superficies pulidas de color marrón-rosáceo con pasta gris claro. Fino desgrasante micáceo y gránulos de óxidos de hierro. Hallado en el estrato IIa2 del Corte M8.

MO-5008. Fragmento de cerámica hecha a molde Superficie roja oscurecida metalizada. Pasta rojizo-rosácea con estrecho núcleo gris claro. Fino desgrasante micáceo. Superficies pulidas. Hallado en el estrato IIb del Corte N9. MO-5009. Fragmento de borde un cuenco hecho a molde. Cerámica roja que por efecto de recocción ofrece un color marrón-grisáceo. Superficies pulidas con resto de espatulado interno y engobe rojo externo. Fino desgrasante micáceo. Hallado en el estrato IIa3 del Corte N9.
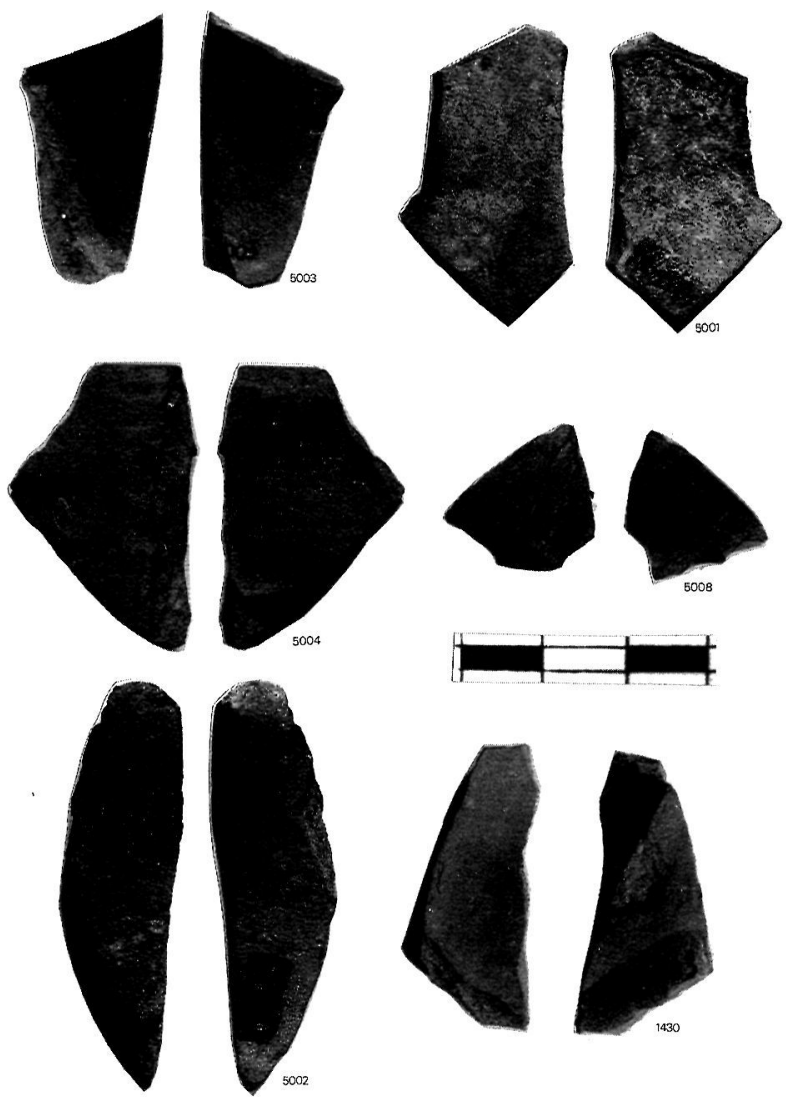

Lám. II.- Cerámica roja monocroma de Les Moreres.

MO-5010. Esquirla de cerámica roja hecha a molde. Superficie pulida y pasta homogénea. Fino desgrasante micáceo. Hallado en el estrato IIa3 del Corte N9.

MO-5011. Fragmento de borde de un cuenco hecho a molde. Superficies pulidas de color rojizo anaranjado con restos de engobe. Pasta roja homogénea con fino desgrasante micáceo. Hallado en el estrato IIa3 del Corte 07.

MO-5012. Fragmento de cuerpo de un cuenco hecho a molde. Cerámica de superficies pulidas de color rosáceorojizo con amplio núcleo gris claro. Fino desgrasante micáceo y gruesas inclusiones de óxidos de hierro. Hallado en el estrato IIa3 del Corte 07.

MO-5013. Fragmento de cuerpo de un cuenco hecho a molde. Cerámica rojiza-rosácea con la pasta en dos tonos anaranjados. Superficies pulidas. Fino desgrasante micáceo y gránulos de óxidos de hierro. Hallados en el estrato IIa3 del Corte 07.

MO-5014. Fragmento de borde de un cuenco hecho a molde de cerámica roja. Pasta rojiza-rosácea casi homogénea. Desgrasante micáceo finísimo con otras inclusiones mayores, entre ellas óxidos de hierro. Superficies erosionadas, en origen pulidas. Hallado en el estrato IIal del Corte 07.

MO-5015. Fragmento de borde de un cuerpo hecho a molde. Cerámica roja en la superficie externa oscurecida 

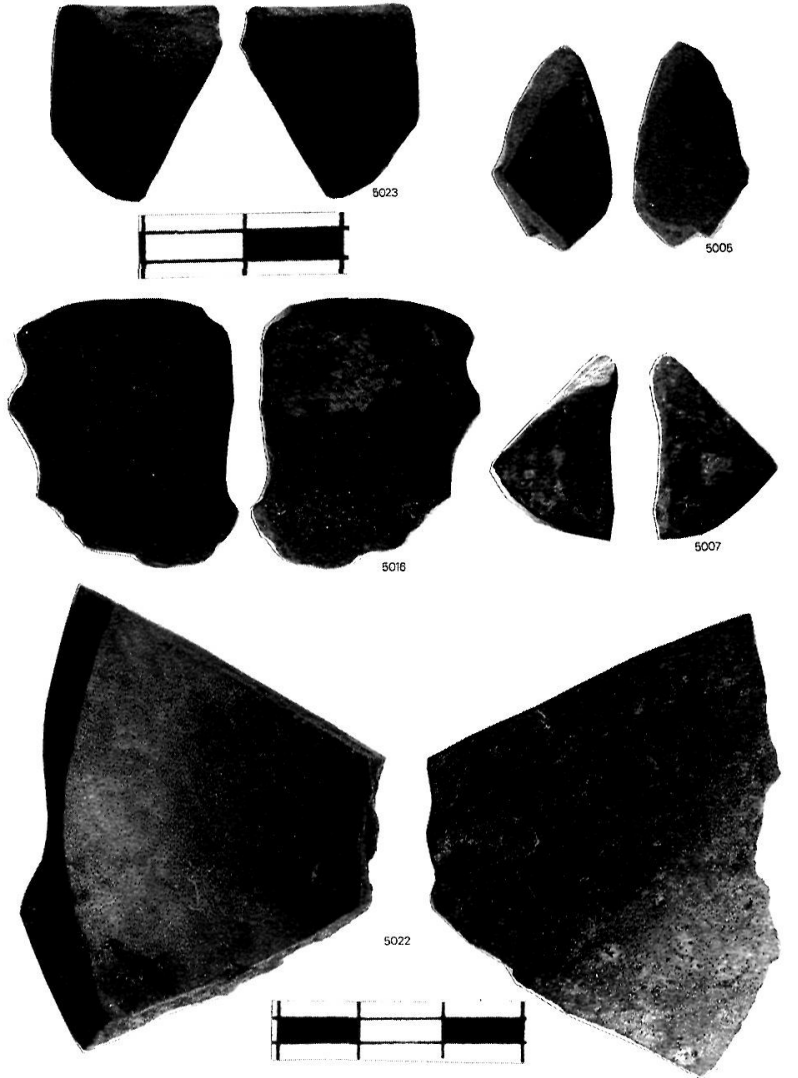

Lám. III.- Cerámica roja monocroma de Les Moreres.

metalizada. Pasta rojizo-anaranjada con leve núcleo gris claro. Superficies pulidas. Desgrasante micáceo muy fino. Hallado en el estrato IIb del Corte 09.

MO-5016. Fragmento de cerámica rosácea hecha a molde. Superficies pulidas. Pasta con núcleo gris y desgrasante micáceo muy fino con óxidos de hierro. Hallado en el estrato IIal del Corte M7.

MO-5017. Fragmento de borde de un cuenco hecho a molde. Cerámica rojizo-anaranjada con superficies pulidas. Pasta homogénea con desgrasante micáceo muy fino y gránulos mayores, entre ellos óxidos de hierro. Hallado en el estrato IIa3-IIb del corte N8.

MO-5018. Esquirla de cerámica roja de un vaso hecho a molde. Pasta rosácea con núcleo gris. Superficie pulida. Fino desgrasante micáceo y gránulos de óxidos de hierro. Hallado en el estrato IIa3-llb del Corte N8.

MO-5019. Fragmento de cerámica hecha a molde de color rojizo-anaranjado. Superficies pulidas. En la exterior, restos de engobe rojizo. Pasta homogénea de color anaranjado. Desgrasante micáceo muy fino. Hallado en el estrato IIa3IIb del Corte N8.

MO-5020. Fragmento de borde de un cuenco hecho a molde. Superficies lisas, en origen pulidas, de color rosáceo-rojizo. Pasta con amplio núcleo gris claro. Desgrasante
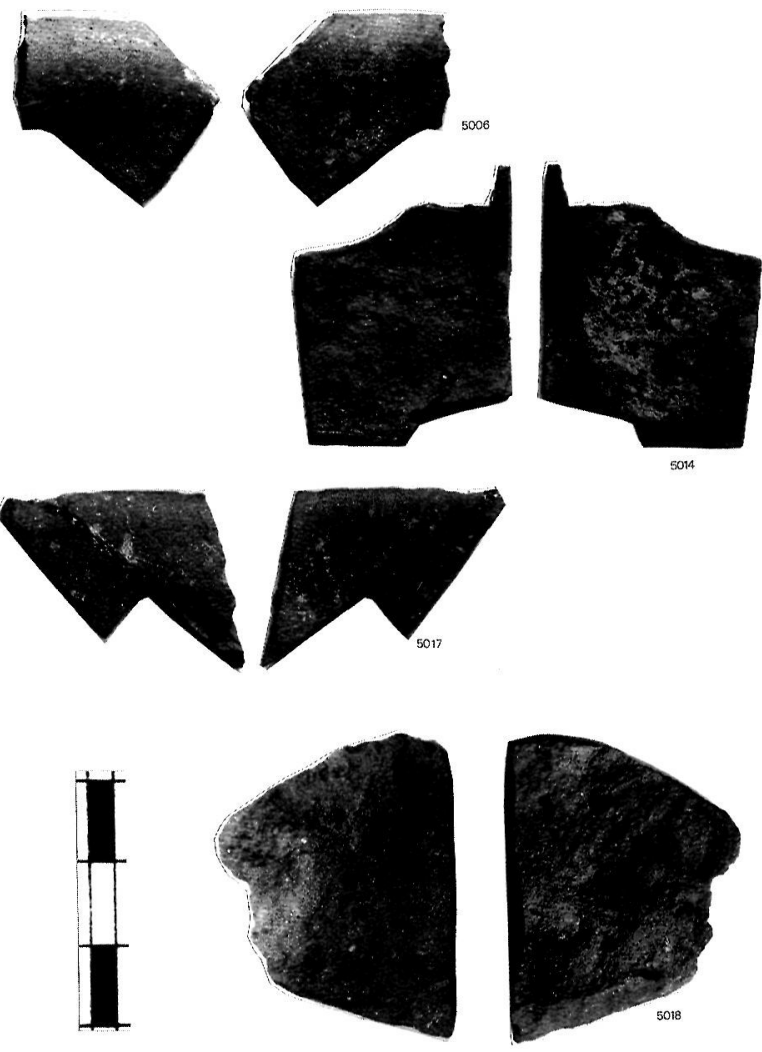

Lám. IV.- Cerámica roja monocroma de Les Moreres.

micáceo muy fino y óxidos de hierro. Hallado en el estrato Ilal del Corte M8.

MO-5021. Fragmento de cerámica hecha a molde de color rosáceo-rojizo alterado por el fuego, lo que le confiere un color marrón-grisáceo con núcleo gris claro apenas diferenciado. Superficies pulidas. Desgrasante micáceo muy fino con óxidos de hierro. Hallado en el estrato II0 del Corte O7 MO-5022. Fragmento del cuerpo de un cuenco hecho a molde de cerámica rosácea. Superficies pulidas. Pasta con amplio núcleo gris claro. Desgrasante micáceo muy fino con gránulos de óxidos de hierro. Hallado en el estrato IIa3Ilb del Corte N8.

MO-5023. Fragmento de borde de un cuenco hecho a molde. Cerámica roja con la superficie externa oscurecida por el fuego. Ambas superficies pulidas. Pasta con leve núcleo gris claro. Desgrasante micáceo muy fino. Hallado en el estrato IIb del Corte N9.

MO-5024. Cuatro fragmentos que unen entre sí y conforman un cuenco hecho a molde de $18 \mathrm{~cm}$. de diámetro y 10 $\mathrm{cm}$. de altura. Cerámica rosáceo-rojiza con diferencias de coloración debido a efecto térmico postcocción. Engobe en la superficie externa y notorio espatulado en la interna. Pasta con amplio núcleo gris claro. Desgrasante micáceo 

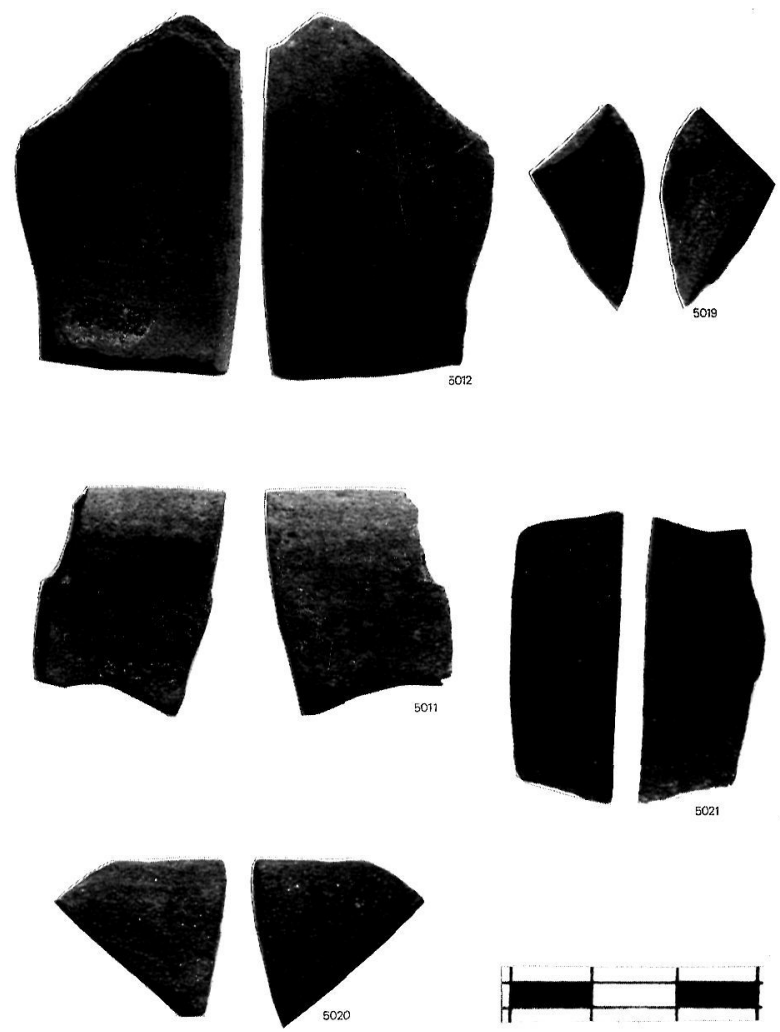

Lám.V.- Cerámica roja monocroma de Les Moreres.

muy fino y gránulos mayores de óxidos de hierro. Hallado en el estrato IIa3-IIb de los Cortes N8-N9.

MO-5025. Fragmento de borde de un cuenco hecho a molde. Cerámica roja con la pasta homogénea del mismo color. Superficies pulidas con restos de engobe en la externa. Desgrasante micáceo muy fíno y otros gránulos mayores. Hallado en el estrato IIa3 de los Cortes N8-N9.

MO-5026. Fragmento de borde de un cuenco hecho a molde. Cerámica roja con la pasta homogénea del mismo color. Borde ligeramente engrosado por el interior. Superficies pulidas con restos de engobe en la externa. Desgrasante micáceo muy fino y gránulos notorios de óxidos de hierro y otros. Hallado en el estrato IIa3 de los Cortes N8-N9.

MO-1394. Fragmento de cerámica hecha a molde. Superficies pulidas de color rosáceo-rojizo. Pasta con núcleo gris claro que encierra otro más interno rojizo. Desgrasante micáceo muy fino y óxidos de hierro. Hallado en el estrato IId de los Cortes JK2'.

MO-1403. Fragmento de cerámica hecha a molde. Superficies pulidas de color rosáceo-rojizo. Pasta homogénea de color gris claro. Desgrasante micáceo muy fino. Hallado en el estrato IId del Corte K2'.

MO-1513. Fragmento de cerámica hecha a molde. Superficies pulidas de color rojo-rosáceo. Pasta homogénea con fino desgrasante micáceo. Hallado en el estrato II del Corte Q2.
Como se habrá observado, la elaboración de estas cerámicas es muy uniforme, con una similar coloración - las variantes se deben a efectos postcocción o postdeposicionales - y una pasta fabricada con arcillas micáceas idénticas para todos los ejemplares. Únicamente cabe hacer una distinción entre aquellos cuyas pastas se presentan homogéneas y los que indican un núcleo de color gris pálido más o menos notorio. En el plano tipológico, debemos llamar la atención sobre la insistencia en la forma de cuenco, ofreciendo una variante profunda al lado de otra más llana. Esta homogeneidad de las arcillas y de la técnica de elaboración nos invita a reclamar un origen único para todos los cuencos que llegan al poblado del Cobre de Les Moreres, exponentes del activo comercio que existe entre los dos extremos del Mediterráneo en la segunda mitad del III milenio a.C.

No dudamos del papel que esta cerámica roja anatólica hallada en el Sudeste jugará a partir de ahora en la problemática sobre las influencias orientales de nuestra Edad del Cobre. De hecho, incide directamente en la tradicional dicotomía sobre difusionismo o indigenismo que hallamos tras determinadas construcciones megalíticas y algunos elementos de la cultura material del calcolítico de la Península Ibérica.

\section{LAS «CERÁMICAS DE IMPORTACIÓN»DE LA EDAD DEL COBRE.}

Veamos, antes de una primera valoración de las cerámicas de Les Moreres, en qué panorama pueden incluirse estos nuevos documentos.

En el marco cultural del III milenio a.C. y en la más pura línea colonialista, un «horizonte de importación» fue establecido (DO PAÇO-SANGMEISTER, 1956) para calificar la fase representada por los registros portugueses precampaniformes (VNSP I).

Uno de los elementos distintivos del bagaje material aportado por gentes alóctonas venía constituido por la cerámica, inicialmente aquellos «copos canelados» (SANGMEISTER-SCHUBART, 1958), relacionados con las píxides egeas del Cicládico Antiguo.

El matrimonio Leisner engrosaría, a principios de los años sesenta, el apartado cerámico importado al incluir la cerámica decorada con motivos incisos o simbólica (LEISNER, 1961a y 1961b) .

En la misma línea, la cerámica pintada almeriense pasó a ser considerada, si no una clara importación sí un producto de las relaciones con el Mediterráneo oriental: 

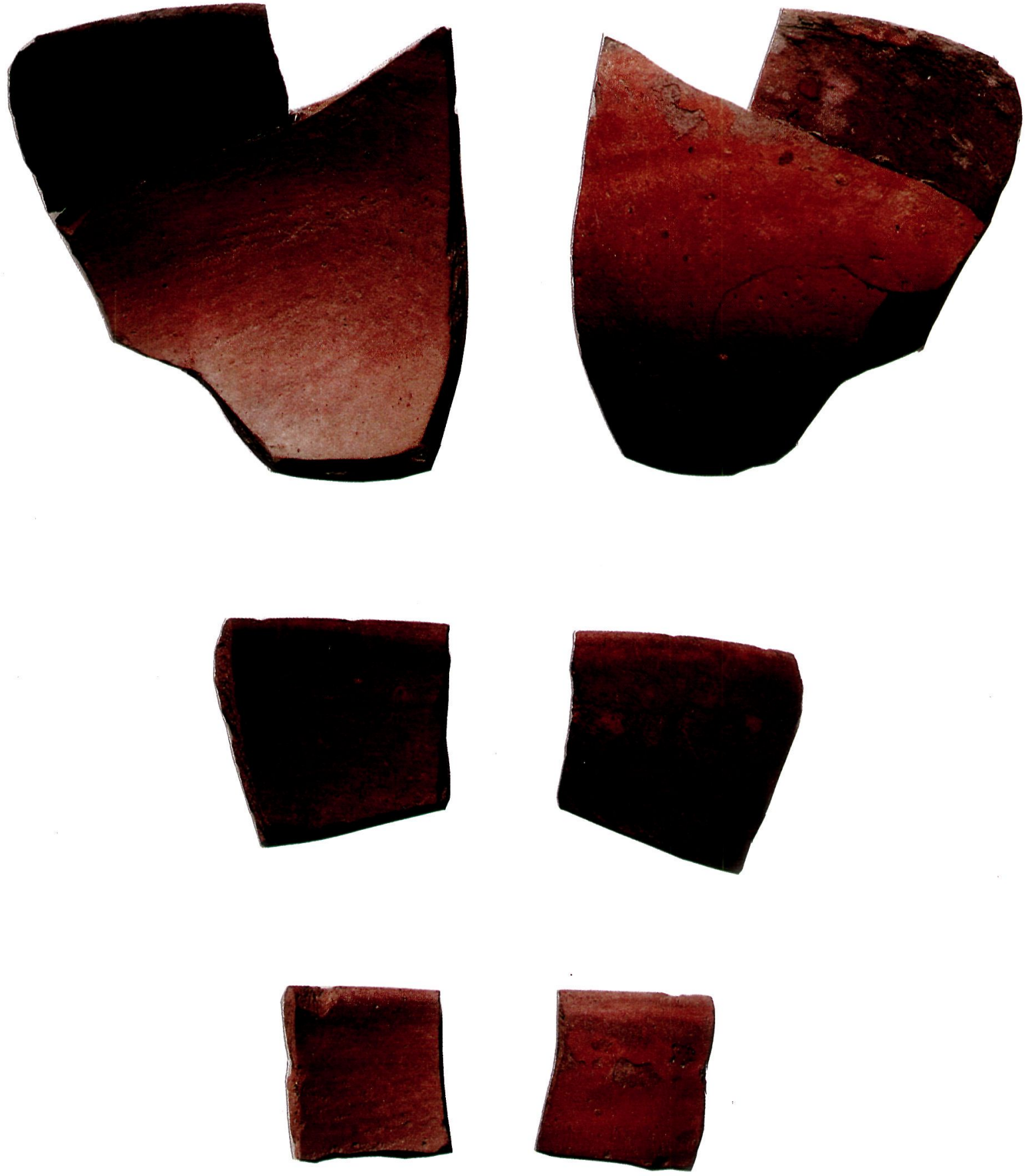

5024

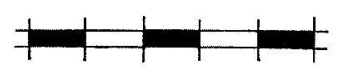

Lám.VI.- Cerámica roja de Les Moreres y aspectos de las pastas en corte. 

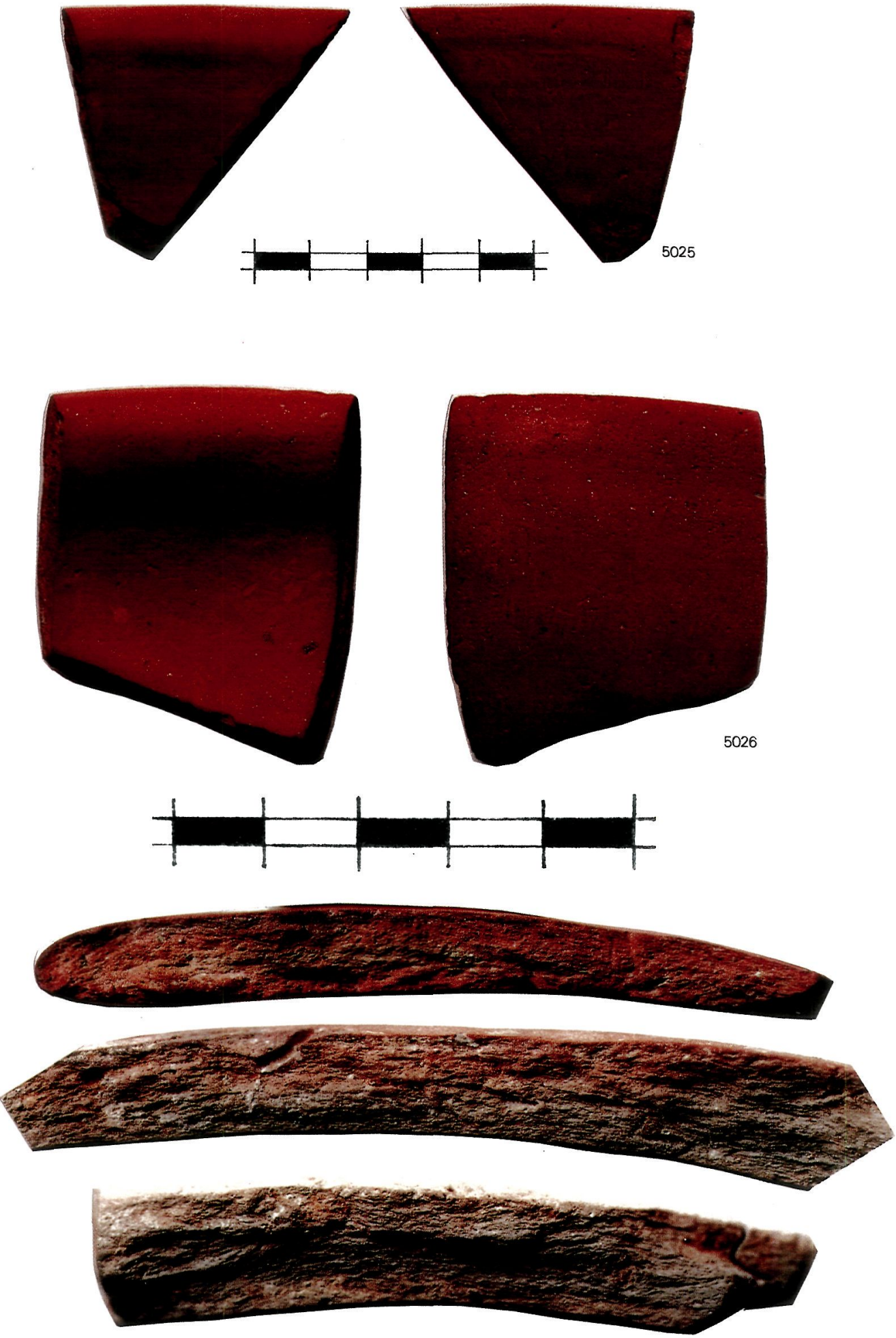

Lám.VII.- Cerámica roja de Les Moreres y aspectos de las pastas en corte. 
«...es importante señalar que todos los especímenes descritos son raros y todos, menos el de Los Millares 21, que no podemos enjuiciar por haberse perdido, nos parecen importaciones, pero esto no es seguro, pues son piezas de arte pobre y, por lo tanto, inciertas, como propias de un centro no determinable... Nosotros creemos que -aún sin mucha precisión en cuanto a su exacto origen local- estos vasos reflejan claras influencias procedentes del Egeo». (ARRIBAS-ALMAGRO, 1963, 233).

Conocemos una referencia única a cerámicas de importación lisas-obviando las diversas valoraciones sobre la cerámica a la almagra—procedente de El Barranquete (Almería):

«...el grupo primero está formado por cerámicas finas, bruñidas o espatuladas, de buena calidad, que ocupan un porcentaje muy pequeño en el total de las cerámicas halladas». (ALMAGRO GOR$B E A, 1973,204)$.

«...pero encontramos también el rojo y el negro brillantes de bruñidos perfectos y pastas más finas que representan solamente un 3,5\% en el poblado y un $10 \%$ dentro de las sepulturas». (Ibidem, 205). "De estas cerámicas, las que mejor nos sirven para ayudar a fechar el yacimiento son las cerámicas de lujo finas con bruñidos brillantes, pues las otras clases más toscas apenas si han sido estudiadas o han llamado la atención de autores y estudiosos de esta etapa cultural... Paralelos de estas cerámicas finas espatuladas y bruñidas encontramos en la misma Península Ibérica, bien fechadas y procedentes, con toda seguridad, como el resto de los materiales, del Mediterráneo Oriental, por lo cual son llamadas por muchos autores «Cerámicas de importación»». (Ibidem, 207).

Al contemplar los paralelos orientales que aducía M. J J. Almagro, en parte coincidentes con los que se manejan en este trabajo, pensamos que ambos estábamos hablando de la misma especie cerámica. Pero la autora claramente está individualizando una producción cerámica hecha a mano, con excelentes acabados, bruñidos o espatulados, con coloraciones rojas o negras. Es decir, la producción de cerámicas finas que hallamos en poblados y tumbas contemporáneos. En modo alguno responde a las características tecnológicas (manufactura a molde, color rojo monocromo uniforme y exclusivo) de las cerámicas objeto de este trabajo.
En el propio registro de Les Moreres disponemos también de una producción de este tipo, con pastas muy delgadas y soberbios bruñidos, cuyo origen local está fuera de toda duda.

Hasta cierto punto resulta comprensible — dado el peso de la tradición orientalista en la investigación peninsular - que una producción cerámica más fina fuera susceptible de convertirse en «un producto mejor, por lo tanto importado». Así entendemos la lógica confusión producida en El Barranquete. Recordemos la presión de las tesis difusionistas, asumidas de modo generalizado en nuestra investigación peninsular: contemplaban la influencia oriental ejercida para algunos a través de auténticas colonias o factorías - sobre aspectos tan diversos del complejo cultural como la arquitectura defensiva, los tholoi, objetos de marfil (peines, ídolos, figurillas,...) o de piedra (vasos, sandalias), alabardas y puñales de sílex, las especies cerámicas mencionadas arriba o la propia metalurgia, por citar los casos más paradigmáticos (Cf. RAMOS MILLAN, 1981. ARRIBAS-MOLINA, 1984. ARRIBAS, 1986. SANTOS GONÇALVES, 1989. CHAPMAN, 1991).

En la década de los setenta se produjo lo que algunos autores consideran un serio revés para las tesis del difusionismo oriental. La calibración de las dataciones de C14 - la denominada segunda revolución del radiocarbono- condujo a $\mathrm{C}$. Renfrew a negar de modo taxativo la dependencia de Occidente respecto de Oriente (RENFREW 1967 y 1989), lo que le llevaría a escribir en 1973:

«...no se habia podido encontrar en la Península lbérica y en el horizonte del Neolítico Reciente o Calcolítico objeto alguno efectivamente importado procedente del Mediterráneo oriental». (RENFREW, 1989, 93)

Lo que se contradice con la afirmación de la existencia de contactos:

«No se puede afirmar, por otra parte, que no pudieran existir contactos entre grupos locales a lo largo de las costas mediterráneas». (Ibidem, 95).

En realidad y pese a valorar las dinámicas autóctonas desde el Neolítico, la ambigüedad cuando no la envergadura de los elementos culturales susceptibles de filiación o de influencia oriental es innegable. Ello explica que determinados investigadores (por ejemplo SCHÜLE, 1980 y 1986) continúen defendiendo un colonialismo llevado a sus últimas consecuencias, mientras otra parte de la investigación no parece defi- 
nirse con claridad. Dos citas de obras recientes ilustran estas posiciones mixtas:

«Sin embargo, la proliferación de hallazgos en los últimos años de sistemas de fortificación con bastiones y torres circulares, cuya cronología puede remontarse en los casos más antiguos al menos hasta comienzos del tercer milenio tanto en ambientes del Mediterrâneo oriental, especialmente en Palestina (Jericó, Ai, Arad), como en el Mediterráneo occidental, por ejemplo en el sur de Francia (Lébous, Boussarges, Camp de Laure), obligan a poner en duda la existencia de múltiples fenómenos de convergencia paralelos y a plantear la posibilidad de un fenómeno de difusión de estos modelos de fortificación, que se irían extendiendo lentamente por todo el Mediterráneo, conectado quizá con el conocimiento de la metalurgia, sin que por ello tengamos que pensar, como se ha venido haciendo en estos últimos años, en contactos directos entre el Mediterráneo oriental y la Península ibérica y aún mucho menos en un fenómeno de colonización a gran escala, promovido por las necesidades de cobre en los mercados del Mediterráneo oriental. Estas últimas hipótesis quedan rotundamente descartadas ante la ausencia total de objetos orientales importados en los yacimientos del tipo MillaresVila Nova de S. Pedro cuyos contextos materiales hunden sus raíces en las tradiciones indigenas de sus respectivas regiones». (ARRIBAS et alii, 1981, 106-107).

«A miragen orientalista só o é pelo seu exagero de formulaçâo. É hoje impossível negar que Vila Nova I, Rotura IIb, por exemplo, mantiveran contactos comerciais e troxaran influências com regiôes do Mediterraneo Central e Oriental ou que as suas cerâmicas traduzem essas influências. Mas será por demais arriscado falar de colonizaçâo». (SANTOS GONÇALVES, 1971, 134).

La afirmación de la inexistencia de importaciones orientales directas en la Península Ibérica, realizada por Renfrew y su escuela, así como por los investigadores del Proyecto Millares, habrá de matizarse, pues, a la luz del hallazgo de estas cerámicas rojas monocromas en Les Moreres.

No creemos que deba descartarse del modo que viene efectuándose la posibilidad de la existencia de objetos de importación mediterráneos en contextos del Cobre peninsular, y menos en una ciudadela como Los Millares.

Es innegable la entidad de los paralelismos para todos esos elementos, que nos esforzamos en considerar autóctonos, en la cuenca oriental del Mediterráneo (Cícladas - Anatolia - Palestina), y en modo alguno la calidad de la documentación arqueológica es tal como para permitir negar la procedencia oriental inmediata de algunos de dichos elementos. Por citar un ejemplo, el impresionante lote de 27 puntas de jabalina de cobre hallado en el dolmen de La Pastora ha venido siendo considerado como una elaboración peninsular (ALMAGRO BASCH, 1962, 34), basándose en su mayor contenido en arsénico respecto a sus paralelos palestinos de Tell-el-Dweir. Sin embargo, desde 2700 a.C. existen en Anatolia objetos elaborados en cobre arsenical (SANGMEISTER, 1960, 137), por lo que las puntas de La Pastora — con paralelos también anatólicos- podrían 'ser objetos importados.

Así las cosas, resulta incuestionable que las cerámicas monocromas de Les Moreres hechas a molde constituyen el elemento cerámico de importación más antiguo en contextos de la Prehistoria reciente peninsular. No se trata de cerámicas «inspiradas» o que «imitan» técnicas foráneas: son verdaderas importaciones. No hace mucho que otras importaciones cerámicas, esta vez a torno y de época micénica, fueron documentadas en Montoro (Córdoba) (MARTIN DE LA CRUZ, 1987 y 1989), buena prueba de las relaciones mediterráneas cinco siglos antes de que aparecieran los colonos y comerciantes fenicios en nuestras costas. Hallazgos como el que aquí presentamos, exponente de los contactos marítimos mediterráneos en el III milenio a.C., invitan a la reflexión sobre la importancia y naturaleza de dichas relaciones en uno de los momentos culturales más fecundos, ricos y complejos de nuestra Prehistoria.

\section{BIBLIOGRAFIA}

ALMAGRO BASCH, M., 1962: El ajuar del dolmen de La Pastora (Sevilla). Sus paralelos y cronología. Trabajos de Prehistoria, V. Madrid.

ALMAGRO GORBEA, Mª J., 1973: El poblado y la necrópolis de El Barranquete (Almería). Acta Arqueológica Hispana, 6. Madrid.

ARRIBAS, A., 1986: «La época del Cobre en Andalucía oriental: perspectivas de la investigación actual». Homenaje a Luis Siret. 159-166. Sevilla. 
ARRIBAS, A. et alii (1981): «Excavaciones en Los Millares (Santa Fe de Mondújar, Almería)». Cuadernos de Prehistoria de Granada, 6, 91-121.

ARRIBAS, A.-ALMAGRO, M., 1963: El poblado y la necrópolis megalíticos de Los Millares (Santa Fe de Mondújar, Almería). Bibliotheca Praehistorica Hispana, III. Madrid.

ARRIBAS, A.-MOLINA, F., 1984: «Estado actual de la investigación del megalitismo en la Península Ibérica». Scripta Praehistorica F. Jordá Oblata, 63-112. Salamanca.

CHAPMAN, R., 1991: La formación de las sociedades complejas. El sureste de la península ibérica en el marco del mediterráneo occidental. Crítica. Barcelona.

DO PAÇO, A.-SANGMEISTER, E., 1956: «Vila Nova de S. Pedro. Eine befestigte Siedlung der Kupferzeit in Portugal». Germania. $34 ; 1-2$.

GONZALEZ PRATS, A., 1983: «La necrópolis de cremación del Bronce Final de La Pena Negra de Crevillente». XVI Congreso Nacional de Arqueología, 285-294. Zaragoza.

GONZALEZ PRATS, A., 1986: «El poblado calcolítico de Les Moreres en la Sierra de Crevillente, Alicante». El Eneolítico en el País Valenciano, 89-99. Alicante.

LEISNER, G. y V., 1961b: «Innenverzierte Schalen der Kupferzeit auf der Iberischen Halbinsel». Madrider Mittelungen, 2, 11-33.

LEISNER, V., 1961a: «Vasos eneolíticos decorados no interior». Revista de Guimarâes, LXXI, 409-428.

MARTIN DE LA CRUZ, J.C., 1987: El Llanete de los Moros
(Montoro, Córdoba). Excavaciones Arqueológicas en España, 151. Madrid.

MARTIN DE LA CRUZ, J.C., 1989: «El Bronce en el valle medio del Guadalquivir». Tartessos. Arqueología Protohistórica del Bajo Guadalquivir, 121-143. Sabadell.

RAMOS MILLAN, A., 1981: «Interpretaciones secuenciales y culturales de la Edad del Cobre en la zona meridional de la Península Ibérica. La alternativa del materialismo cultural». Cuadernos de Prehistoria de Granada, 6, 203-256.

RENFREW, C., 1967: «Colonialismus and megalithismus». Antiquity, XLI.

RENFREW, C., 1989: El alba de la Civilización. La revolución del radiocarbono y la Europa prehistórica. Madrid.

SANGMEISTER, E., 1960: «Metalurgia y comercio del cobre en la Europa prehistórica». Zephyrus, XI (1-2), 131-139.

SANGMEISTER, E.-SCHUBART, H., 1958: ««Import-Keramik» de Vila Nova de Sao Pedro», en DO PAÇO, A.: «Castro de Vila Nova de Sâo Pedro. X Campanha de escavaçôes». Anais, 8.

SANTOS GONÇALVES, V.M. dos. 1989: Megalitismo e Metalurgia no Alto Algarve oriental. Uma aproximaçâo integrada. 2 vols. UNIARQ. Lisboa.

SCHÜLE, W., 1980: Orce und Galera. Zwei Siedlungen aus dem 3. bis I. Jahrtausend v. Chr. im Sïdosten der Iberischen Halbinsel, l. Mainz am Rhein.

SCHÜLE, W, 1986: «El Cerro de la Virgen de la Cabeza, Orce (Granada): consideraciones sobre su marco ecológico y cultural». Homenaje a Luis Siret, 208-220. Sevilla.

\section{SEGUNDA PARTE}

\section{LA TRADICIÓN ANATÓLICA DE CERÁMICA MONOCROMA DURANTE EL BRONCE ANTI- GUO (III MILENIO A.C.)}

En función de las características distintivas de esta cerámica monocroma roja hallada en Les Moreres en relación con lo que viene siendo usual en los contextos del Cobre peninsular barajamos la hipótesis de que podría tratarse de una importación.

Siguiendo la idea de que se tratase en realidad de una importación oriental iniciamos la búsqueda de posibles paralelos en los países ribereños del Mediterráneo, habida cuenta de que en la Prehistoria

* Agradezco la colaboración y los consejos prestados por Dominik Bonatz, Joaquín Córdoba, Hans Curvers, Elisabeth Donatello, Gönül Egeli, Ufuk Esin, Gian María di Nocera, Winfried Orthmann, Rosa María Moreno Pelayo, así como a Harald Hauptmann y el Institut für Ur-und Frïhgeschichte und Vorderasiatische Archäologie de la Universidad de Heidelberg. Un especial agradecimiento debemos a Manfred Korfmann y su equipo de excavación de Troya, asi como a Machteld Mellink. continental europea centro-occidental se carecía de precedentes para este tipo de cerámica.

La región donde mayor posibilidad de relación se presentaba era la costa del Oriente Próximo y el Mediterráneo oriental durante el tercer milenio a.C., observándose un fenómeno de dispersión de su influencia, que a continuación se detalla — todas las zonas del Egeo durante el tercer milenio muestran importantes influjos del Bronce Antiguo (BA) de Anatolia y de la zona sirio-Cilicia-.

En el Egeo se observa un fenómeno de evolución cultural, con diferentes variantes regionales - Cicládico Antiguo (CA) en las Cícladas, Heládico Antiguo (HA) en la Heláde, Minoico Antiguo (MA) en Creta, y Chipre, con una facies cultural calcolitica que llega hasta aproximadamente el 2400 cuando comenzará el Bronce Antiguo en la isla-, caracterizadas por la aparición casi súbita de metalurgia y nuevas técnicas cerámicas más depuradas. En el HA I hay muchos nuevos yacimientos con sólo presencia de cerámica monocroma, a menudo engobada en rojo y pulimentada (WEINBERG, 1965, 303). D. French ve estrechas relaciones entre los típicos cuencos del HA I y los del 


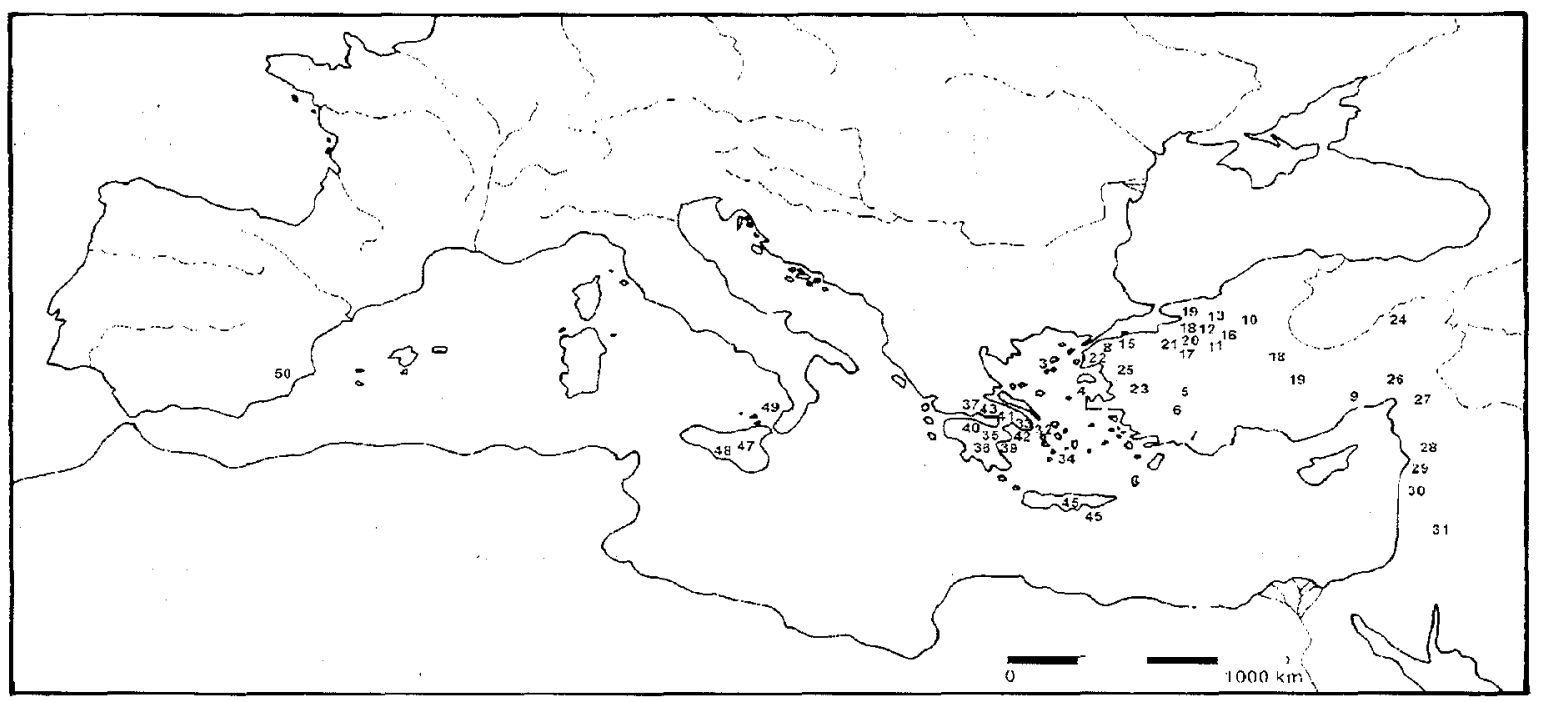

Fig. 1.- Mapa de los lugares citados en el texto. 1. Samos Herion; 2. Samos Tigani; 3. Poliochni; 4. Thermi; 5. Beycesultan; 6. Aphrodisias; 7. Karata, 8. Troya; 9. Tarso; 10. Etiyokusu; 11. Demirci; 12. Cukurhisar; 13. Aharkoy; 14. Kusura; 15. Kumtepe; 16. Demirkoy; 17. Inegol; 18. Karasil; 19. Kinik; 20. Pazaryeri; 21. Yeni ehir; 22. Besiktepe; 23. Egrikoy; 24. Alaca; 25. Uyucek; 26. Gedikli; 27. Zincirli; 28. Tell Sukas; 29. Qalat ar-Rus; 30. Biblos; 31. Jericó; 32. Chalandriani; 33. Ayia Kirina; 34. Monte Kynthos; 35. Korakou; 36. Zygouries; 37. Eutresis; 38. Orchomenos; 39. Lerna; 40. Corinto; 41. Ayios Kosmas; 42. Tirinto; 43. Tebas; 44. Kanli Kastelli; 45. Partira; 46. Ayios Nicolaos; 47. Malpaso; 48. Serraferlichio; 49. Lipari; 50. Les Moreres.

BA I y II anatólico en Beycesultan, Anatolia suroccidental (FRENCH, 1961, 117). Esta cerámica con relaciones anatólicas la encontramos en diversas zonas de la Hélade; Korakou, Zygouries, Eutresis, Orchomenos, Lerna y Corinto, son algunos de los sitios más destacados que presentan esta cerámica. El hecho cobra mayor importancia durante el HA II -período en el cual se ha pretendido situar según la historiografía tradicional la existencia de migraciones de gentes anatólicas en la Heláde (WEINBERG, 1965, 304) - cuando aparece, durante sus inicios, una nueva categoría cerámica, la especie Urfinis, cerámica pulimentada caracterizada por una capa de engobe rojo de un mayor espesor y brillantez que los ejemplares hallados en Moreres, y a diferencia de la monocroma - de la cual su aspecto diverge-, la Urfinis presenta decoración pintada (CASKEY, 1960 , 160, 285-303). Cerámica de este tipo se encontró principalmente en el grupo VIII de Eutresis y en Lerna III. Cabe la posibilidad de que este tipo de técnica, presente entre algunas importaciones de mediados de la fase Troya I, podría haber llegado desde las Cícladas (WEINBERG, 1965, 304) si no desde las costas occidentales deAnatolia - Samos, Poliochni y los diversos lugares de la Troiade-. Además en
Macedonia hay materiales con semejanzas a los de Anatolia occidental durante las fases Troya I-II (Ibidem, 1002).

Ha sido muy comentada la estrecha conexión que el Egeo ha tenido con Troya (HUOT, 1982, 995) y con Anatolia. En las Cícladas durante el tercer milenio (CA I-III) las superficies de la nueva tradición de cerámicas pulimentadas presentan un color marrón oscuro (WEINBERG, 1937, 516). Las importaciones cicládicas figuran además entre otros aspectos de la cultura material de la Hélade durante el HA II, como atestiguan la fortificación del asentamiento de Lerna, construida de manera similar a la de Chalandriani en Syros (CASKEY, 1958, 132-36), y enterramientos en Ayios Kosmas, con paralelos en las prácticas de enterramiento cicládicas (CASKEY, 1964, 14; MYLONAS, 1959, 64-120).

Se considera el carácter exclusivamente autóctono cicládico de los materiales pues todas las culturas cicládicas presentes durante el tercer milenio a.C. Grotta-Pelos, Keros-Syros y Phylakopi- muestran contactos con Anatolia occidental, especialmente fuertes paralelos en diversos lugares como Kastri/Chalandriani (Syros), Ayia Kirina (Keos), Monte Kynthos (Delos) durante la cultura de Keros-Syros, 
caracterizada por la profusión del uso del metal, con muchas formas cerámicas — cuencos, jarras, salseras y dépas entre ellas-presentes en Troya, Samos, Poliochni, e incluso en Beycesultan, es decir Anatolia suroccidental (RENFREW, 1972, 170 ss., HUOT, 1982, 1009 ss.). M. Mellink ha interpretado las primeras intrusiones de carácter anatólico suroccidental, presentes en lugares como Aphrodisias y Karatas como propias de la transición BA II-III, es decir c. 2600-2200, (MELLINK, 1992, 217). Recientemente se enfatiza el papel de las influencias anatólicas en las Cícladas, las cuales alcanzarían su máximo apogeo durante el CA II B (RUTTIER, 1984; COLEMAN, 1992) o el CA III A (BARBER, 1987; MacGILLIVRAY, 1984).

En la Argólida, Lerna, durante el HA II, muestra una cerámica monocroma relacionada posiblemente con estos influjos anatólicos pero diferente de la aparecida en el Cobre de Les Moreres — la heládica muestra un esmaltado/vitrificado totalmente ausente en las cerámicas halladas en Les Moreres - . En la Hélade durante esta fase lo más constatable son las muestras de arquitectura de una cierta envergadura y presuntos edificios públicos en esta región, hecho que parece tener su paralelo en la zona anatólica occidental, donde el yacimiento de Troya II parece ser contemporáneo con Lerna III. En Tirinto hay un gran tholos (CASKEY, 1960, 288) semejante a la construcción encontrada en los niveles del III milenio a.C. debajo del templo de Heraion en Samos, situado en la costa occidental de Anatolia (MILOČ́̌ , 1961, 27). Los influjos anatólicos en la cultura material de Tebas (Grecia Central) y Lefkandi I (Eubea) son, asimismo, evidentes (cf. COLEMAN, 1992).

Durante el Minoico Antiguo, la isla de Creta guarda relaciones con Anatolia occidental, especialmente con la zona de Troya. Es interesante la aparición en el MA I de una cerámica pulimentada con engobe rojizo en la isla. En Kanli Kastelli, Partira y Ayios Nikolaios, esos elementos cerámicos (MORTZOS, 1972; WARREN, 1972), relacionan a la isla con Troya I-IV, Thermi I-V, Poliochni IIb-III y el BA II de Tarso (HUOT, 1982, 1012 ss.). Se ha comentado la posibilidad de inmigraciones desde Anatolia noroccidental como explicación para las nuevas corrientes culturales presentes desde el MA I en la isla (WARREN, 1974).

En Chipre, la aparición de una cerámica monocroma roja bruñida - llamada por los excavadores red polished ware -, fabricada a mano, durante el Bronce Antiguo local o período Chipriota Antiguo (24002000), se viene considerando como uno de los elemen- tos integrantes del conjunto de novedades aportadas por un supuesto influjo anatólico (Cf. KARAGHEORGIS, 1967; MELLINK, 1966; 1991).

Se ha venido hablando de la existencia de un cierto difusionismo desde Anatolia para explicar los cambios existentes en la Hélade, Cícladas y áreas circundantes, especialmente durante el período HA II. Muy recientemente esta hipótesis sigue siendo considerada la más válida explicación para todas esas nuevas apariciones de otra cultura material —enterramientos, arquitectura-, incluyendo la presencia de formas cerámicas anatólicas, en Macedonia, Eubea, Tebas y las Cícladas (COLEMAN, 1992, 265).

Vista la evidencia de las fuertes relaciones e influjos culturales anatólicos existentes durante el III milenio a.C. en el área geográfica del Mediterráneo oriental, emprendimos una investigación en las tradiciones cerámicas de Anatolia, especialmente el área occidental durante su Bronce Antiguo I B-III, es decir el III milenio a.C., período en el cual, precisamente, se dió la tradición de cerámicas monocromas de pastas rojas. Las cerámicas del poblado del Cobre de Les Moreres entroncan con esa tradición cerámica anatólica.

En el Mediterráneo central, por otro lado, debemos señalar la presencia en Malpasso (Sicilia), en tumbas colectivas, de cerámica monocroma roja de inspiración anatólica, ajena a la cultura material de la isla, según Brown (BROWN, 1965, 331). Ignoramos si se trata de las mismas producciones que las halladas en la costa alicantina. Cerámicas rojas monocromas - junto con una variante negra- de análogas características, se hallaron en Serraferlicchio, contempladas también como un influjo del Mediterráneo oriental.

En Lípari (islas Eolias) aparecen cerámicas monocromas pulimentadas importadas — semejantes a las de Poliochni, Troya y Samos- en la cultura de Piano Quartara.

La cerámica roja de Les Moreres se encuentra, en Anatolia noroccidental, bien estratificada en las fases contemporáneas con Troya II - yacimiento cuya secuencia sirve de referencia para el área-, en el área de Iznik. En esta zona han sido halladas dos variedades dentro de la cerámica monocroma de pastas rojas, la red washed, y la red burnished (Cf. FRENCH, 1967).

La primera variante, red burnished, es una cerámica monocroma fina elaborada a mano, que presenta pastas con una variada gama de rojos, además de grises; hay siempre inclusiones de mica y presenta un baño o engobe rojizo, con una superficie bien puli- 
mentada (FRENCH, 1967). En la prospección efectuada por D. French en la zona de Iznik esta categoria cerámica se advirtió en la mayor parte de los lugares prospectados. Su datación se pensó «contemporánea con Troya II, Beycesultan XVI-XIII, Demirci Höyük, y todas las variantes de cerámica red slipped and burnished de Anatolia occidental» (FRENCH, 1967, 61). La otra variante, red washed, es una cerámica fina de pastas rojas o marronáceas, elaborada a mano o a torno, con altas temperaturas de cocción, y presencia de pequeñas micas entre los desgrasantes. La superficie está bien pulimentada y tiene un color generalmente rojizo debido a un baño. D. French la dató contemporánea a las variantes de red wash encontrada en Troya III-V (realmente es la red coated ware con sólo la nomenclatura cambiada) o en Beycesultan XIIVI, donde está pendiente la cuestión de que haya sido introducida ya en Beycesultan XIII, equivalente a algunas fases finales de Troya II (LLOYD-MELLAART, 1962).

En las áreas de Balikesir y Akhisar/Manisa Anatolia Noroccidental aparecen cerámicas monocromas de pastas rojas. Al igual que la zona de Iznik aparecen dos variantes. Una es llamada red slipped, la variante típica de la zona occidental de Anatolia - es la red washed de la zona de Iznik, y la red coated de Troya-, una cerámica elaborada a mano y a torno (FRENCH, 1969, fig. 13. 23-35; 14. 1-27). Su arco temporal se sitúa en Troya II-V y Beycesultan XIIXVI. La otra variante de cerámica monocroma de pastas rojas, es la red burnished, cerámica fina de pastas rojas pulimentada y engobada en rojo, con inclusiones minerales como micas y cuarcitas, una variante local sólo apareció en Akhisar/Manisa (FRENCH, 1969, f. 9. 1-27). Su cronología es un poco posterior a la anterior, pero dentro del III milenio a.C.

En uno de los yacimientos de Anatolia noroccidental, Demirci Höyük, situado en la región contigua a Iznik, Eskisehir, disponemos de una cerámica monocroma roja de pastas rojas, pulimentada y engobada, la cual presenta una gradación de colores dentro de la gama del rojo; además hay cerámicas de pastas grises y negras - también con diversa gama de variantes-, pero presentando incluso el mismo pulimentado y engobado en rojo (BITTEL-OTTO, 1939, lám. 9,2). Esta cerámica roja es predominante en los niveles superiores de la secuencia del sitio, que acabaría a fines de Troya II, lugar con el cual parece ser contemporáneo en esos niveles (BITTE-LOTTO, 1939, 30). Cerámica con pulimentado y engobado rojo análoga a la de Demirci fue hallada en los cercanos lugares de Çukurhisar y Aharköy Höyük (BITTEL-OTTO, 1939, 31).

En la zona suroccidental de Anatolia, la isla de Samos ha proporcionado interesantes restos en distintos contextos del Bronce Antiguo. En el área debajo del Heraion, se encontró una cerámica monocroma de pastas rojas, pulimentada, con la supeficie externa con un engobe rojo con diversas variantes de color. Igualmente aparecieron cerámicas monocromas con pastas grises-negras y marrones (Cf. MILOJCIC, 1961, 44), también en muchos casos con engobe en una variada gama de rojos.

Anatolia suroccidental muestra en Beycesultan la existencia de cerámicas monocromas de pastas rojas, con engobe también rojo durante la fase Beycesultan XIIIa (LLOYD-MELLAART, 1962, 56, 190, f. P46, 1-6). Tenemos la mejor referencia en Beycesultan XIV-VIII, que se desarrolla durante el BA II anatólico. Karatas, lugar situado en la llanura de Elmali, muestra en una serie de enterramientos en pithoi y viviendas hallazgos de cerámicas análogas datadas durante el BA II-III (MELLINK, 1964). Otro sitio interesante es Kusura (LAMB, 1937, 1938) con materiales del BA I-III.

En la zona de la Tróiade, costa occidental de Anatolia, el yacimiento de Troya II ha demostrado la existencia de estrechas relaciones con el fenómeno expansivo producido en Cilicia, costa sudoriental de Anatolia, durante el BA III local, según diversos autores (Cf. GOLDMAN, 1956, 131. MELLINK 1965a, 115; 1989. HUOT. 1982).

La Tróiade presenta diversas variantes dentro de la tradición de cerámicas monocromas de pastas rojas —en ocasiones con núcleo gris_ indistintamente elaborada a mano o a torno, bruñida y engobada, con micas entre los desgrasantes minerales y consistencia dura y compacta. El espeso engobe de la superficie suele presentar diversas tonalidades del rojo, - de rojo anaranjado claro a rojo púrpura- siendo más rosáceo en las fases finales de Troya II. Se pulimentan mucho los cuencos Ilanos de la fase IIc, y en cambio los cuencos semiesféricos presentan una tenue capa de revestimiento rosáceo, rojo o tostado, con o sin brillo (BLEGEN et alii, 1950, 221).

Existe en Troya otra categoría cerámica, también variante de la monocroma, llamada plain ware, caracterizada por pastas finas rojas y grisáceas, cocida a altas temperaturas, a torno y quizás a mano, sin engobe; en las últimas fases de Troya II esta cate- 
goría cerámica aparece elaborada con pastas marronáceas, además de presentar un aspecto poroso pero consistente, por lo cual se la ve como un desarrollo de la cerámica llamada gritty de Cilicia (cf. BLEGEN et alii, 1950, 224).

El material cerámico de Troya II tiene mucho en común con Tarso BA III A. Para M. Mellink Troya no sólo influencia a Tarso durante el BA II de Anatolia, sino que la zona noroccidental recibe influjos del área cilicia (MELLINK, 1965a). Los platos de gran tamaño rojo brillantes de los inicios de Tarso BA IIIA tenían un engobe bruñido brillante (GOLDMAN, 1956, 133) como los que aparecen en Troya IIc como característicos (BLEGEN et alii, 1950, 224-225, 274-75). Los platos más tardíos en ambos lugares presentan un engobe levemente lustroso, pálido y marronáceo (GOLDMAN, 1956, 133) o una capa muy tenue de rojo rosáceo tostado (BLEGEN et alii, 1950, 221), los cuales no aparecen en las posteriores fases de Troya III-IV que cierran el milenio.

Un importante foco nuclear de cerámica monocroma rojiza del Bronce Antiguo parece situarse en la zona de la llanura sudanatólica — región que no contemplamos como probable origen de las cerámicas encontradas en Les Moreres, pero sí estrechamente relacionada con la problemática-, la zona de las regiones de Konya y Capadocia. Aparecen imitaciones e importaciones de cerámicas propias de la zona occidental en Anatolia central, sugiriendo además las semejanzas entre los metales de ambas áreas la existencia de estrechas relaciones (MELLINK, 1989, 328), anteriormente vistas por otros investigadores como muy atenuadas (HUOT, 1982). Kültepe BA IIIB es uno de los ejemplos de los contactos entre ambas áreas durante el período. Esta zona ha mostrado algunas estrechas semejanzas en sus cerámicas con las de la zona de Cilicia, durante el BA I-II de Anatolia (MELLAART, 1963) -debemos tener en cuenta que este autor iguala los períodos del Bronce Antiguo en la secuencia de Cilicia y la zona de Konya-.

En la región de Konya ya a fines del BA II, momento que J. Mellaart colocó c. 2300 a.C., la inmensa mayoría de los lugares mostraban cerámicas monocromas rojas finas elaboradas a mano, raramente decoradas, salvo el pulimentado, presentando a menudo engobe. Esta cerámica mostraba diversas tonalidades de rojo, en ocasiones con pulimentado de color naranja; suelen aparecer además núcleos grises en las pastas. Mellaart advirtió una distribución dispersa de las cerámicas rojas pulimentadas en toda la zona central y occidental de Konya, tanto en las llanuras de Çumra y Karaman, como en Beyşehir, Seydişehir y el valle de Kalykadnos (MELLAART, 1963, 211).

Junto con la cerámica roja pulimentada apareció otra categoría cerámica, presente desde el BA I de Anatolia, la llamada metallic ware, cerámica elaborada a mano con altas cocciones; presenta inclusiones calcáreas y de sonido metálico, y a menudo con pintura mate. En esta categoría aparece una variante llamada red gritty, diferente de la homónima categoría en la zona de la costa cilicia. Las pastas con núcleos grises son casi nulas. Su aspecto difiere de las cerámicas de pastas rojas que ocupan nuestra investigación, aunque algunas peculiaridades técnicas puedan remitir a ellas. La distribución de esta cerámica metálica es muy amplia en el centro y este de Konya, así es muy común en la llanura de Karaman, el valle de Kalykadnos, y en la llanura entre Eregli y Bor (MELLAART, 1963). La variante red gritty apareció en Kanaç (Karaman) y alrededor de Ulukis, siendo menos común en el área de Çumra - Konya, y muy escasa en el valle del río Çarsamba (lbidem).

Mellaart, en su prospección de la llanura sudanatólica, advirtió restos de cerámicas rojas bruñidas - la red polished de Troya (BLEGEN et alii, 1950)—, y un depas - cerámica y forma típicos de Troya II,-y en el sitio de Üçhöyük, al cual atribuyó una cronología del BA III de Anatolia (MELLAART, 1963, 236).

La llanura de Konya también muestra una interesante perspectiva con yacimientos excavados como Karahöyük V-VII, donde durante el BA II hay en su fase VII la metallic ware; la cerámica metálica de la zona de Konya parece tener diferente fábrica respecto a la red gritty de Cilicia (MELLINK, 1993). Hay un amplio uso en el BA III en Konya de engobe rojo para cuencos realizados a mano. Otro lugar excavado, Acemhöyük muestra cerámica metálica durante los niveles 9-10, junto con cerámica monocroma de engobe rojo propia de Anatolia occidental (ÖZGÜÇ, 1980).

Varios yacimientos de Anatolia central como Alisar Höyük 6M-5M y 12 T, Alaca Höyük III, Kültepe 14 (ÖZGÜÇ, 1963) al igual que los lugares excavados o prospectados de la llanura sudanatólica, proveen un volumen importante de cerámica monocroma roja indistintamente hecha a mano — variedad predominante- y a torno. Cerámica centroanatólica 
del tipo Alisar aparece repentinamente (MELLINK, 1965a, 112) en pequeñas cantidades entre las importaciones de Tarso al inicio del BA IIIa cilicio, mayoritariamente en forma de cuencos rojos simples (GOLDMAN, 1956, 134-35).

En Alaca Höyük las cerámicas monocromas proceden principalmente de las tumbas reales, una serie de tumbas en pozo, supuestamente elaboradas para las familias de las élites en el poder, sin seriación estratigráfica - diversos intentos fueron efectuados por Kurt Bittel (1959, 28-30) y Winfried Orthmann (1963, 32-34) —. En estas tumbas apareció material cerámico del BA II e inicios del BA III. Los ajuares pueden correlacionarse con Troya II y los yacimientos del Cicládico Antiguo (BITTEL, 1959).

La tradición centro-anatólica de cerámica monocroma a mano cambió hacia el 2000 a.C. según Huot (1982), momento en el cual aparece en Alisar $5 \mathrm{M}$, una nueva cerámica monocroma a torno, junto con la llamada cerámica de Capadocia, una variedad pintada que aparecería desde el BA IIIb cilicio.

La zona de Cilicia, costa sureste de Anatolia, muestra una profusión de diversas variantes de cerámicas de pastas rojas - durante el BA III estas van a suponer la casi totalidad del corpus cerámico de Tarso (MELLINK, 1989, 325) - . En el BA II cilicio, 27002400 a.C., la zona tiene ya extensas conexiones con la zona occidental de Anatolia. Además de contactos con diferentes zonas de Anatolia occidental, muestra relaciones con el Levante y Chipre, las cuales M. Mellink juzga comerciales (MELLINK, 1993). En la región de Cilicia existe durante las fases I-III del Bronce Antiguo local de Tarso, actual Gözlï Küle, el mejor conocido de los sitios del BA de la zona, un fósil director tan característico como es la plain and burnished red gritty ware, una cerámica monocroma rojiza fabricada indistintamente a torno o a mano - esta variante en mayor proporción-, con bruñido, cuya superficie puede haber recibido un engobe del mismo color - el pulimentado y su aspecto brillante tiende en las fases más tardías a parecerse a un baño rojo (GOLDMAN, 1956, 132) - La pasta es homogénea e incluye abundantes desengrasantes minerales, a base de micas, calizas y cuarcitas. El espatulado tiende a tener mejor calidad a fines del período (Ibidem). Esta cerámica roja durante el BA IIIA de Tarso, 2400-2200 a.C. (MELLINK, 1991, 168-9), va a presentar nuevos rasgos que la diferencian de la tradición de cerámicas rojas monocromas anatólicas, mayoritariamente a mano y con pintura de aspecto brillante - de ahí su calificativo de metálica-, presentes durante el Bronce Antiguo I y II de Tarso, cuyas altas temperaturas de cocción se pensaron introducidas por grupos de ceramistas anatólicos del área de Nigde-Konya (MELLINK, 1989, 320). Esta tradición anatólica, de raigambre local, de cerámicas rojas a mano, predomina también en el BA II de Tarso, y son preferentemente elaboradas a mano (GOLDMAN, 1956).

La red gritty ware de Cilicia es difícil de distinguir, en varias ocasiones de la light clay ware, cerámicas de colores claros, a torno lento (MELLINK, 1989, lám. 59,5), también bruñida, en la cual se utilizan desgrasantes similares, además de un buen espatulado, y cocida a menores temperaturas que la roja de tradición anatólica pero sí adquieren un rojizo semejante con alta cocción. La presencia de estas cerámicas claras se conecta con una tradición cerámica pretendidamente siria, presente en Tarso desde su BA I (GOLDMAN 1956, fig. 236, 50-52), pero que en el BA II de Tarso se han catalogado como una producción local (MELLINK, 1989, 320 ss.), siendo de un tipo más fino que las plain simple wares del 'Amuq G y H (GOLDMAN, 1956, ff. 245, 178-87). Además existe otra nueva categoría cerámica que aparece repentinamente en el BA III de Tarso, la red-slipped burnished ware, a mano o a torno, con bruñido rojizo, de mayor brillo en las fases iniciales, y cuyas pastas - con núcleo gris en ocasiones - parecen una variante de la orange brittle ware del 'Amuq (GOLDMAN, 1956, 132, f. 264. 400402, 405). Según H. Goldman parecen una mezcla de las cerámicas light clay y red gritty (GOLDMAN, 1956,132 ). Esta cerámica ha sido relacionada estrechamente por su tratamiento de superficies con la red coated ware de Troya II (GOLDMAN, 1956, 134) — se ha pensado en la existencia de un fuerte impacto cultural proveniente del oeste de Anatolia sobre el BA III de Tarso, impacto que se extiende considerablemente en Anatolia (MELLINK, 1989, 326 ss.)-.

En Tarso BA III hay otra categoría de cerámica importada de aspecto metalizado, la metallic ware, semejante a la que se ve en el 'Amuq I-J (MELLINK, $1962 ; 1965 a)$, pero el valle del Éufrates superior parece la zona originaria de esa cerámica metálica, presente en Tarso ya durante el BA II, diferente de la metálica centro anatólica (MELLINK, 1965a, 111). En Tarso se realizaron imitaciones de esta cerámica metálica siria en grey o red-slipped gritty ware, con bruñido. En base a ello se ha supuesto una conexión con el área de 
Gedikli y Zincirli, donde también apareció cerámica análoga de aspecto metálico de origen sirio.

La súbita presencia de las innovaciones cerámicas de Troya II y Tarso BA IIIa ha llevado a Mellink hacia la suposición de un centro en el oeste de Anatolia para esas nuevas apariciones, quizás Aphrodisias (MELLINK, 1992, 216) —en Aphrodisias Complejo VI se ha hallado en cantidad cerámica monocroma de pastas rojas con engobe, presumiblemente elaborada a torno (KADISH, 1971), semejante a las pastas rojas troyanas y cilicias-.

En la región del 'Amuq, aparece la llamada redorange brittle ware, una cerámica bruñida de pastas rojas, y en ocasiones con una fina capa de engobe igualmente rojizo, con una superficie que presenta toda una gama de tonos entre el rojo y marrón (BRAIDWOOD, 1960). En la zona interior contigua a la costa cilicia, en el área de Sakçagözü, esta cerámica de pastas rojas, red-orange brittle ware, aparece en Gedikli III (ALKIM, 1966), Tilmen Hoyuk (BRAIDWOOD, 1960), y Zincirli (BRAIDWOOD, 1960, 518).

En el 'Amuq durante las fases $\mathrm{H}$ e I, es decir desde el 2600/2500 a.C., se halla esta variante cerámica en calidad de importación, con un porcentaje sensible, que oscila entre el 1 y el 6\% (BRAIDWOOD, 1960), es decir, en cantidades nada abundantes. Según los análisis de Matson su arcilla presentaba materiales volcánicos (BRAIDWOOD 1960. WATSON, 1965, 78). Los ejemplares de esta cerámica aparecidos en Cilicia tienen pastas semejantes a la del 'Amuq. Pese a tratarse de una cerámica diferente a la encontrada en Les Moreres, sus características técnicas son semejantes, pareciendo las cerámicas monocromas de pastas rojas una variante de esta brittle ware según Winfried Orthmann.

En la costa sirio-palestina, especialmente en la franja donde más tarde se centra el desarrollo de las civilizaciones cananea y fenicia, Tell Sukâs, Qalat arRûs y Biblos KI muestran además cerámicas rojas monocromas importadas elaboradas a mano, existiendo una producción a torno en un momento avanzado del tercer milenio (2200-2100).

Por lo que respecta a Palestina, cerámicas de pastas rojas aparecen durante el BA III de la zona, datado c.2400-2000. La principal constatación de estas cerámicas de probable origen alógeno proviene de las tumbas A94, F3 y F4 de Jericó (KENYON, 1960, 126-146, ff.43.13, 16 y 18, 51.11, lám. III.2) cuyos ejemplares están realizados a torno.

\section{LA TRADICIÓN DE CUENCOS SEMIESFÉRICOS Y LLANOS EN EL MEDITERRÁNEO ORIENTAL (TERCER MILENIO A.C.)}

Dentro del repertorio tipológico que ofrecen las diversas variantes de cerámica monocroma de pastas rojas anatólica, son precisamente las formas halladas en el Cobre de Les Moreres, el cuenco profundo y el cuenco llano, dos de los tipos más característicos de su producción, los cuales igualmente se presentan, en ocasiones -en Anatolia occidental durante el BA II y en Cilicia durante el BA IIIa- fabricados en otras especies de cerámica monocroma, la de pastas grises y la de pastas negras.

Las características tipológicas que presentan son un cuenco con paredes hemiesféricas, borde redondeado o apuntado, fondo indeterminado, sin decoración, con un bruñido, y en ocasiones un engobe rojizo. En la variante del cuenco llano, los bordes tienen un engrosamiento interior. Los cuencos perviven hasta fines del tercer milenio a.C.

Un repertorio de cuencos de tipo anatólico occidental en pastas rojas - la cerámica red polished del BA III en Tarso y Troya II, lugar este último desde donde podrían haberse expandido a Cilicia-, se dan en diversos yacimientos de Anatolia occidental como Karatas próximo a Elmalî (MELLINK, 1965b, 1967) y Aphrodisias, suroeste de Anatolia. En Aphrodisias se encuentran cuencos llanos de pastas rojas con engobe, especialmente en el Complejo VI de la Acrópolis (KADISH, 1971, lám. 30, f. 39. JOUKOWSKY, 1986).

En Samos, en la costa suroccidental, aparecieron multitud de cuencos con pastas rojas y engobes rojizos o con pastas grisáceas - con variada gama cromática dentro de las dos variantes - ya sean con las paredes rectas (MILOJCIC, 1961, lám. 35. 42), o predominantemente semiesféricos -algunos de los cuales mostraron una larga continuidad no sólo en el sitio (Ibidem, láms. 45. 36), sino en Troya desde el período II (Cf. BLEGEN et alii, 1950, forma A 16)-, en diferentes contextos del yacimiento del Bronce Antiguo - una serie de fragmentos de cuencos fueron encontrados en una zona de viviendas quemadas (MILOJCIC, 1961, 49, láms. 39. 13, 44. 5-6, 14, así como una interesante forma de cuenco llano (Ibidem, lám. 39. 14). Otros aparecieron en áreas funerarias, en tumbas tipo pithos (Ibidem, láms. 22. 9); finalmente algunos se encontraron en hoyos (Ibidem, láms. 35. 26-27, 48- 
$51,59,63 ; 36.5 ; 37.38,49,53-55)$ en contextos temporales análogos a Troya II-IV.

Varios de los cuencos presentes en lugares de la zona de Eskisehir (Demirci Höyük, Etioyokusu) tienen paralelos con otros hallados en zonas del interior de Anatolia (Cf. HUOT, 1982, formas A1.1121, A1.1131).

La región de Karatas Semayük (EASTON, 1976), antigua Licia, presenta diversos cuencos llanos durante el BA III de Anatolia, formas comunes por otro lado con el BA IIIc de Tarso.

Los cuencos presentes en Kumtepe Ib también muestran excelentes paralelos para los ejemplares de Les Moreres. Estos cuencos de Kumtepe podrían haber influenciado a los tipos de cuencos cicládicos.

En Troya II algunas de las formas de cuencos de pastas rojas presentes en la categoría cerámica llamada por el equipo de la Universidad de Cincinnati, red coated ware, se dan además en la categoría llamada plain ware (BLEGEN et alii, 1950, f.370a. A 2, A 16), donde esos cuencos simples aparecen sin engobe. Los cuencos, supuestamente todos elaborados a torno según sus excavadores, de la forma A2 de Troya II, presentan inclusiones minerales como micas y se elaboraron con alta cocción, apareciendo en grandes cantidades y predominantes dentro de la categoría red coated en algunos sectores de la excavación. Estos cuencos recuerdan a ejemplares de Tarso BA III en sus niveles superiores (BLEGEN et alii, 1950, 226, f. 372). Las bases de los cuencos en ambas categorías cerámicas son planas. Algunas formas — como la A 16 de Blegen (cf. ibid.)—muestran asas horizontales semejantes a las aparecidas en cuencos de Tarso.

Los cuencos llanos de la muy común forma A1 de la categoría red coated en Troya II (cf. ibid.) recuerda a cuencos llanos en la red polished ware de Tarso BA III durante sus primeras fases (GOLDMAN, 1956).

Los cuencos de red coated ware en Troya II aparecen presuntamente con mayores cantidades no en las fases iniciales del período, sino desde la fase IId (BLEGEN et alii, 1950, 299).

En el área anatólica noroccidental de Iznik aparecieron cuencos a mano como una de las formas más típicas de la cerámica monocroma de pastas rojas red burnished (FRENCH, 1967) contemporánea con la fase Troya II-, en los yacimientos de Demirköy (Ibidem, figs. 8. 30-43), Inegöl II (Ibidem, ff. 10. 2124), Karasil I (Ibidem, ff. 13. 28-30), Kinik (Ibidem, ff. 14. 11,1418), Pazaryeri I (Ibidem, ff. 17. 36-38, 40-
43) y Yenisehir I (Ibidem, f. 20. 42). Los diámetros de los cuencos oscilan entre 11 y $30 \mathrm{~cm}$.

También la otra variedad de cerámica roja presente durante el III milenio en el área de Iznik, la red washed, presenta entre las formas más típicas cuencos de paredes rectas o con carena, que muestran las líneas verticales y radiales del pulimentado (FRENCH, 1967, 61).

El yacimiento de Demirci Höyük, situado en la zona de Eskisehir, Anatolia noroccidental, aportó una considerable cantidad de cuencos semiesféricos (BITTEL-OTTO, 1939, f.8, 1, 4, 7-8, 12, 14, 17, 20, 23, 24), elaborados con pastas rojas, pulimentados y con engobe (Ibidem, lám. 8. 8, 17).

Entre los cuencos aparecidos en Besik Tepe, yacimiento de la misma área, hay similitudes con los cuencos profundos y llanos de Les Moreres (cf. SEEHER, 1985. lám. 17, LL83, 34/6 46/1. 31/1, 31/3, 24/12). Estos cuencos también han hallado paralelos en Kumtepe IA y B.

En Beycesultan XIII son frecuentes los cuencos de pastas rojas presentando engobe interno y externo rojo, durante el BA IIA y IIB.

En la zona de la llanura sudanatólica, región de Konya, aparecieron cuencos en cerámica monocroma de pastas rojas, pulimentada (MELLAART, 1963, f.8, $5,7,16,18)$ los cuales son también elaborados en otra variante, cerámica monocroma de pastas negras. Las bases de los cuencos semiesféricos generalmente presentan un pequeño omphalos (MELLAART, 1963, f. 8.9). Mellaart advirtió semejanzas de los cuencos de cerámica monocroma de pastas rojas pulimentados elaborados a mano de esta zona con cuencos del BA II de Tarso (GOLDMAN, 1956, f.345).

En Cilicia los cuencos tienen una larga tradición durante todo el III milenio, dependiente o no de sus contactos con la zona occidental de Anatolia. Tarso muestra ya durante su BA I, cuencos en cerámica fina clara engobados y elaborados a torno, presentes en pequeñas cantidades (GOLDMAN, 1956, f.236, 5052; MELLINK, 1989, lám. 58, 2a y b). Una de las características tipológicas del BA II en Tarso son los cuencos en pastas claras, de inspiración siria, elaborados con torno lento y buena cocción (GOLDMAN, 1956, f.245. 155. MELLINK, 1989, lám. 59, 1 y 2), vistos como una derivación de los cuencos elaborados a torno del BA I en Tarso, pero los nuevos presentan un mayor diámetro -entre 12 y $22 \mathrm{~cm}$.-, y mostrando todavía el engobe en círculos de sus predecesores, 
durante los inicios de esta fase, cuando constituyen el $20 \%$ de las cerámicas encontradas en ámbitos domésticos (MELLINK, 1989, 321) —en su día, H. Goldman opinó que el cuenco no estaba bien representado hasta el BAIII de Tarso, siendo escasos anteriormente (GOLDMAN, 1956, 131) los cuencos de pastas claras parecen ser reemplazados por cuencos rojos elaborados a torno durante la fase BA II.8 en Tarso, previa al colapso del asentamiento durante la fase siguiente (MELLINK, 1989).

H. Goldman mencionó entre las variantes de cuencos con pastas rojas con engobe y bruñido durante Tarso BA III, una que mostraba las pastas claras y era elaborada a torno y con inclusiones micáceas (GOLDMAN, 1956, f.355. 389-90).

Realmente será durante el período siguiente en Tarso, BA III, cuando los cuencos monocromos de pastas rojas, en red gritty ware, abunden en el repertorio de Cilicia. Los más característicos son el cuenco sin asa (GOLDMAN, 1956, 264. 383) durante los inicios del período, así como cuencos con leve carena, los cuales presentan un asa horizontal en las fases más tardías (GARSTANG-GOLDMAN, 1947, 384. GOLDMAN, 1956, ff. 267. 430, 354. 433). En los ámbitos domésticos del período ya no aparecerán cuencos en pastas claras semejantes a los de Tarso BA II (MELLINK, 1989, 324).

Por otra parte, entre las formas de cerámica de pastas rojas originaria de Anatolia occidental, la red polished de Troya (BLEGEN et alii, 1950) - especialmente en las fases Tarso BA III. 1 y 2 , destacan por su cantidad los cuencos semiesféricos simples elaborados a mano, los cuales junto a los cuencos llanos constituyen casi $1 / 5$ parte del corpus cerámico del período. Los semiesféricos presentan a menudo carenas (GOLDMAN, 1956, 264. 400-403). Los cuencos llanos presentaban supuestas marcas de torno (GOLDMAN, 1956, 353. 429). Hay además que anotar la presencia en gran cantidad durante los inicios del período, de cuencos llanos, con claras marcas de torno, formas típicas del noroeste de Anatolia (GOLDMAN, 1956, f.265. 413). En las fases más tardías, la forma de cuenco con trípode también típica del noroeste anatólico en Troya continúa hasta la fase $\mathrm{V}$ - aparecerá en Tarso (GOLDMAN, 1956, 355. 445).

Se piensa que los cuencos de Tarso eran destinados para raciones de comida (MELLINK, 1989, 325). Lo cierto es que generalmente aparecen cuencos con diámetro medio superior a $25 \mathrm{~cm}$.
En Anatolia central, Alaca Höyük y Üyücek Tepe en el área del río Sakarya son los mejores paralelos que contamos para una variante concreta del cuenco profundo (Cf. HUOT, 1982, forma A1.1133) cuya dispersión está muy localizada.

En las regiones periféricas de Anatolia, que muestran cerámica monocroma de pastas rojas, estas formas alógenas de cuencos dan la impresión de tratarse de una moda de importación muy floreciente en un momento dado, que finaliza antes de los dos últimos siglos del tercer milenio.

Los yacimientos de la Hélade tienen durante el HA II varias formas de cuencos (Cfr. CASKEY, $1968,314)$, los cuales no presentan paralelos con las formas de cuencos hallados en Les Moreres. Los cuencos aparecidos en Eutresis (Cfr. CASKEY-CASKEY, 1960, f. 11. VIII.6, lám. 50. VIII.1-2, 21), Lerna III (Cfr. CASKEY, 1960, 290, f. 1 A-E), y también Korakou, Asiné y Zygouries presentan paredes rectas, sin engrosamiento interno en los bordes, carencia de bases esféricas y sí presencia de bases planas o con pie.

En las Cícladas no se aprecian tampoco similitudes entre cuencos semiesféricos y llanos de fabricación local aparecidos en Antiparos (FORSDYKE, 1925, lám. IV. A 319), Chalandriani, Amorgos (FORSDYKE, 1925, 59, lám. IV. A 327) y los ejemplares de Les Moreres. Los cuencos profundos y llanos de las Cícladas muestran bases planas y a modo de omphalos, y los bordes introversos.

En Palestina durante el BA III un tipo importado de cuenco semiesférico aparece en Jericó. En Palestina este tipo de cuencos no aparece en otros lugares del BA II o III palestino, salvo Jericó, y aparentemente en contextos funerarios. La tumba F4 muestra diversos cuencos - que ofrecen paralelos interesantes con los hallados en Les Moreres-. Así tenemos el tipo F.2.a (Cf. KENYON, 1960, f.43.13), un cuenco de forma cónica de cerámica roja elaborada a torno. El tipo F.4.a (KENYON, 1960, f. 43.15) es un cuenco de cerámica de color rosáceo, fondo amplio y algo profundo. También la tumba F3 (KENYON, 1960, f.51) muestra cuencos con analogías a los de Les Moreres: lados curvados, sin decoración, base circular, amplios y poco profundos.

La forma MO-5000 tiene paralelos con cuencos aparecidos en Anatolia noroccidental, caso del yacimiento de Demirci Höyük (BITTELOTTO, 1939, lám. 8.14). 
La forma MO-5004 es un tipo de cuenco semiesférico con dispersión en Anatolia noroccidental (FRENCH, 1969).

Las formas MO-5006 y 5011, dos tipos de cuencos llanos, con el borde engrosado en el interior, tienen excelentes paralelos con los cuencos llanos aparecidos en Aphrodisias, un yacimiento de la costa mediterránea de Anatolia (KADISH, 1971, f. 39).

La forma MO-5011, un cuenco llano con el borde engrosado en el interior y paredes ovoides, presenta analogías con cuencos de pastas rojas de tamaño medio con engobe rojo aparecidos en Egriköy (FRENCH, 1969, f.14, 5-6), Anatolia noroccidental.

Las formas MO-5014 y MO-5015 son semejantes a una forma con una amplia dispersión en Anatolia. Sus paralelos más semejantes son cuencos aparecidos en diversos lugares de la llanura sud-anatólica (MELLAART, 1963, f. 8, 16) y en Anatolia sudoccidental (FRENCH, 1967, f. 14, 17)

La siguiente forma hallada, MO-5017, presenta analogías con formas procedentes de la zona de Iznik, es decir la Anatolia noroccidental, en lugares como Demirköy, Inegöl II y Karasil I (FRENCH, 1967, ff. 8, 40;10, 23; 13, 29). También es una forma característica de Demirci Höyük (BITTEL-OTTO, 1939, lám. 9.2). También aparece en el Heraion de Samos (MILOJIC, 1961, lám. 37. 49), Samos Tigani (HEINDEREICH, 1936), y Tarso (GOLDMAN, 1956, 127).

La forma MO-5024 de Moreres corresponde a un cuenco semiesférico con paredes ovoides de amplia dispersión en Anatolia occidental. Los ejemplares encontrados en Demirci Höyük (BITTEL-OTTO, $1939,20$, f. 8,17 , láms. $8.8,12,20,24)$ son una buena referencia.

La forma MO-5026, un cuenco llano con base esférica, también presenta semejanzas con cuencos aparecidos en la zona de Iznik, en los lugares de Demirköy, Egriköy (FRENCH, 1967, f. 8, 38; 14, 5).

\section{CONCLUSIONES}

- Concluimos que las cerámicas de pastas rojas halladas en Moreres tienen sus más estrechos paralelos en dos tipos de cuencos, uno llano y otro más profundo cuya distribución parece difundirse en Anatolia ya con el Bronce Antiguo I, en la zona occidental de Anatolia (Iznik, Eskisehir, la Troiade,
Anatolia sudoccidental) con algunos ejemplares en la llanura sudanatólica.

La asociación de cerámicas de pastas rojas junto a pastas grises y negras, es un hecho no sólo presente en las diversas zonas de Anatolia donde aparece cerámica monocroma de pastas rojas, sino en varios lugares del Egeo oriental y Mediterráneo oriental. Ello habla a favor de la dispersión de una influencia cultural cerámica anatólica en zonas insulares del Mediterráneo oriental.

Por ello no se descarta el hecho de la posible aparición de las variantes de pastas grises y negras que suelen asociarse a algunas de las formas cerámicas encontradas en Les Moreres en posteriores campañas de excavación en el poblado.

Con el hallazgo de las cerámicas del Mediterráneo oriental presentes en el Cobre de Les Moreres, vuelve a reactivarse la cuestión de las conexiones existentes entre los dos extremos del Mediterráneo, incluso de su existencia clara durante el transcurso de la segunda mitad del III milenio a.C.

Por último, resulta significativo que, como ya ha sido señalado por algunos especialistas (MELLINK, 1993), la difusión de las cerámicas rojas monocromas tanto en Anatolia como en el Mediterráneo oriental y central, coincida con un floremiento generalizado de la metalurgia, manifestado en la producción de nuevos tipos metálicos en el desarrollo de la orfebrería. ¿Cabría plantearse si este fenómeno, ocurrido entre 2700-2100 .C., pudo haberse producido también en la Península Ibérica?

\section{BIBLIOGRAFIA}

ALKIM, U.B. y H., 1966: «Gedikli (Karahüyük) Kazlsl Birinci Önrapor/Excavation at Gedikli (Karahüyük); first preliminary report». Belleten, XXX, 1-57. Ankara.

BARBER, R.L.N., 1987: The Cyclades in the Bronze Age. University of Iowa Press. Iowa City.

BITTEL, K., 1959: «Beitrag zur Kenntnis anatolischer Metallgefässe der Zweiten Hälfte des dritten Jahrtausend v. Chr.». Jahrbuch des Deutschen Archäologischen Instituts, 74, 1-34. Berlín.

BITTEL, K.-OTTO, H., 1939: Demirci Hüyük, Eine Vorgeschichtliche Siedlung an der Phrygisch-Bithynischen Grenze. Bericht über die Ergebnisse der Grabung von 1937. Archäologisches Institut des Deutschen Reiches. Estambul-Berlín.

BLEGEN, C. et alii, 1950: Troy, General Introduction. The First and Second Settlements, Vol.1. Princeton University Press. Princeton.

BRAIDWOOD, D. y L., 1960: Excavations in the Plain of Antioch vol. 1. The Earlier Assemblages Phases A-J. Oriental Institute Publications LXI. University of Chicago Press. Chicago. 
BROWN, D.F., 1965: «The Chronology of the Northwestern Mediterranean». Chronologies in Old World Archaeology, $2^{a}$ ed., 321-342.

CASKEY, J.L., 1958: «Excavations at Lerna, 1957». Hesperia, XXVII, 125-144. Atenas.

- 1960: «The Early Helladic Period in the Argolid». Hesperia XXIX, 285-303. Atenas.

- 1964: «Investigations in Keos, 1963». Hesperia XXXIII, 31435. Atenas.

- 1968: «Lerna in the Early Bronze». American Journal of Archaeology, 72, 313-316. Nueva York.

CASKEY, J.L.-CASKEY, E.G., 1960: «The Earliest Settlements at Eutresis: Supplementary Excavations, 1958». Hesperia XXIX, 126-67. Atenas.

COLEMAN, J.E., 1992: "Greece, the Aegean, and Cyprus». Chronologies in Old World Archaeology, 3" ed. vol. 1. University of Chicago Press. Chicago-Londres.

DIKAIOS, P., 1962: «The Stone Age», Swedish Cyprus Expedition, Vol. IV. 1A, 1-204. Estocolmo.

EASTON, D.F., 1976: «Towards a Chronology for the Anatolian Early Bronze Age», Anatolian Studies, XXVI, 145-73. Londres.

FORSDYKE, E.J., 1925: Catalogue of the Greek and Etruscan Vases in the British Museum, vol. 1, Part 1, Prehistoric Aegean Pottery. Londres.

FRENCH, D.H., 1961: «Late Chalcolithic Pottery in NorthWest Turkey and the Aegean». Anatolian Studies, XI, 99-141 Londres.

- 1967: «Prehistoric Sites in North-West Anatolia, I, The Iznik Area». Anatolian Studies, XVII, 49-100. Londres.

- 1969: «Prehistoric Sites in North-West Anatolia, II, Balîkesir and Akhisar/Manissa Areas». Anatolian Studies XIX, 14-98. Londres.

GARSTANG, J.-GOLDMAN, H., 1947: «A Conspectus of Early Cilician Pottery». American Joumal of Archaeology, LI, 370388. Nueva York.

GOLDMAN, H., 1956: Excavations at Gözlü Kule, Tarsus, vol.II. From the Neolithic through the Bronze Age. Princeton University Press. Princeton.

HEIDENREICH, R., 1936: «Vorgeschichtiliches in Samos. Die Funde $»$. Athenische Mitteilungen, 60-61, 124-183. Atenas.

HÖCKMANN, O., 1987: «Frühbronzezeitliche Kulturbeziehungen im Mittelmeergebiet unter besonderer Berücksichtigung der Kykladen». Ägäische Bronzezeit, 53-120. Darmstadt.

HUOT, J.L., 1982: Les céramiques monochromes lissées en Anatolie à l'époque du Bronze Ancien. Geuthner. París.

JOUKOWSKY, M., 1986: Prehistoric Aphrodisias, vol. 1. Providence-Lovania.

KARAGHEORGHIS, V., 1967: La civilisation préhistorique de Chypre. Atenas.

KADISH, B., 1971: «Excavations of Prehistoric Remains at Aphrodisias, 1968 and 1969». American Journal of Archaeology, 75, 121-140. Nueva York.

KENYON, K., 1960: Excavations at Jerico, vol. 1: The Tombs excavated in 1952-54. British School of Archaeology in Jerusalem. Londres.

LAMB, W., 1937: «Some West Anatolian Vases at Cambridge». Annual of the British School at Athens, XXXVII, 166-171. Londres.

- 1938: «Excavations at Kusura near Afyon Karahisar: II». Archaeologia 87, 217-273. Londres.

LLOYD, S.-MELLAART, J., 1962: Beycesultan, vol. I. British Institute of Archaeology at Ankara. Londres.
MacGILLIVRAY, J.A., 1984: «The Relative Chronology of Early Cycladic III». The Prehistoric Cyclades, 70-77. Edimburgo.

MELLAART, J., 1963: «Early Cultures of the South Anatolian Plateau, II. The Late Chalcolithic and Early Bronze Age in the Konya Plain». Anatolian Studies, XIII, 199-236. Londres.

MELLINK, M.J., 1962: «The Prehistory of Syro-Cilicia», Bibliotheca Orientalis, XIX, 219-26. Leiden.

- 1964: «Excavations at Karatas-Semayük in Lycia». American Journal of Archaeology, 68, 269-278. Nueva York.

- 1965a: «Anatolian Chronology». Chronology in Old World Archaeology, 101-131. Chicago-Londres.

1965b: «Excavations at Karatas-Semayük in Lycia, 1964». American Joumal of Archaeology, 69, 241-251. Nueva York.

1966: «Excavations at Karatas-Semayük in Lycia, 1965». American Joumal of Archaeology, 70, 245-257. Nueva York.

1967: «Excavations at Karatas-Semayük in Lycia, 1966». American Joumal of Archaeology, 71, 251-267. Nueva York.

1989: «Anatolian and Foreign Relations of Tarsus in the Early Bronze Age». Studies in Honour of Tahsin Özgü̧, 319-331. Ankara.

1991: «Anatolian Contacts with Chalcolithic Cyprus». Bulletin of the American Society of Oriental Research 282-3, 167-175.

1992: «Anatolian Chronology». Chronologies in Old World Archaeology, vol. 1, 207-220. Chicago-Londres.

1993: "The Anatolian South Coast in the Early Bronze Age». Between the Rivers and over the Mountains, 495508 Roma.

MILOJCIC, V., 1961: Samos, Band I, Die prahistoriche Siedlung unter dem Heraion, Grabungen 1953 und 1955. Habelt Verlag. Bonn.

MORTZOS, C., 1972: «Partira, mia proimos Minoike Kerameike Omas». Epeteris Epistemonikon Ereunon, 386-421. Atenas.

MYLONAS, G.E., 1959: Aghios Kosmas. An Early Bronze Age Settlement and Cemetery in Attica. Princeton University Press. Princeton.

ÖZGÜÇ, T., 1963: «Early Anatolian Archaeology in the Light of Recent Research», Anatolia, VII, 1-42. Ankara.

PELTENBURG, E.J., 1982: Recent Developments in the Later Prehistory of Cyprus. Studies in Mediterranean Archaeology, 16. P. Åströms Förlag. Goteburgo.

- 1990: «Chalcolithic Cyprus». Cyprus before the Bronze Age. Art of the Chalcolithic Period, 6-22. Malibú.

RENFREW, C., 1972: The Emergence of Civilization. The Cyclades and the Aegean in the Third Millenium B.C. Methuen. Londres.

RUTTER, J.B.. 1984: «The Early Cycladic III Gap». The Prehistoric Cyclades, 95-107. Edimburgo.

SEEHER, J., 1985: «Vorläufiger Bericht über die Keramik des Besik-Sivritepe». Archäologischer Anzeiger 2, 172-182

WARREN, P., 1972: Myrtos, An Early Bronze Age Settlement in Crete. British School of Archaeology at Athens, Supplementary vol. 7. Oxford

- 1974: «Crete, 3000-1400 B.C.: Inmigration and the Archaeological Evidence». Studi Micenei ed Egeo-Anatolici, 17, 205-19. Roma.

WATKINS, 1981: «The Chalcolithic Period in Cyprus: The Background to Current Research», Chalcolitic Cyprus and Westem Asia, 9-20. Londres.

WEINBERG, S.S., 1970: «The Stone Age in the Aegean». Cambridge Ancient History, 1, 1, 557-672. Londres. 


\section{TERCERA PARTE}

\section{ANÁLISIS CERÁMICOS}

\section{Métodos y análisis}

Por lo ya descrito nos encontramos ante unas cerámicas muy distintas a las que generalmente se presentan en los yacimientos del Cobre Pleno y Final en el Sureste peninsular. Dada la problemática que pueden representar hemos efectuado algunos análisis para la caracterización cerámica; a los que se añadirán, en el futuro, otros en cordinación con los estudios en curso de otros fragmentos similares constatados en algunos yacimientos del Sureste Español.

Los métodos utilizados en estas cerámicas han sido la lupa binocular, lámina delgada y la difracción de Rayos X (XRD).

Mediante la lupa binocular hemos podido observar una clara orientación de los desgrasantes de forma paralela a las paredes de los vasos, orientación que se vuelve anárquica en la zona del labio y que nos puso en guardia sobre su manufacturación. En primer lugar, parece haberse fabricado, por un lado, el cuerpo del vaso y por otro, se habría adosado posteriormente el labio. Los desgrasantes que se pueden apreciar son micáceos, y de forma articular en algunas muestras aparecían escasos fragmentos de obsidiana, elemento este claramente ajeno a nuestra zona de estudio y que nos puso en la pista de que podría tratarse de un material importado. El tamaño de estos desgrasantes es muy pequeño y la compactación de la cerámica es muy buena, con una porosidad muy baja.

En lo que respecta a la cochura, dada la coloración se observa que las piezas fueron cocidas en atmósfera oxidante durante todo el proceso (que debió de ser muy prolongado), no observándose, dada su uniformidad, contacto alguno con materia orgánica, es decir, no se aprecian signos de estar cocidas con los tradicionales hornos cerámicos compuestos por un hoyo en la tierra cubierto por ramajes u otros materiales orgánicos. Este hecho nos está sugiriendo la existencia de hornos con una mayor complejidad, es decir, donde se separa claramente la cámara de combustión y el laboratorio, o incluso, de tiro invertido como ya aparecen atestiguados en algunos yacimientos calcolíticos (Vilanova de São Pedro, Portugal, PAÇO, 1957)

El tratamiento de las superficies se hace de dos formas distintas, un grupo de cerámicas presentan un espatulado muy fino que se ejecuta de forma perpen- dicular a las paredes del vaso, y un segundo grupo en el que se aprecia un tratamiento a base de engobe de fina capa que le confiere en algunos casos un aspecto casi metálico.

Con respecto a la utilización de los vasos, no se detectan sobre las superficies de los mismos marcas de haber sido expuestos al fuego, sobre todo en las áreas más proclives para ello (en la cara interna, zona central y fondo; en la cara externa, zona inferior), asimismo no se han detectado huellas de lavado, a excepción de dos fragmentos que sí que presentan algunas marcas superficiales en trazos paralelos. Este hecho nos pondría en la pista de ser unos vasos especiales que no se utilizan como vajilla de cocina, y por otro lado, dada su escasez y localización dentro del yacimiento, podrían tener unos fines particulares, llegando incluso a formar parte como elemento más de prestigio o relacionarse con el contenido de determinados líquidos, como así lo corrobora la baja porosidad de los vasos (entre un 14,71 y un 15,47\%). Lo cierto es que serían unos vasos con un cierto valor, como ya se apuntó para el yacimiento de El Malagón (ARRIBAS et alii, 1978, 76).

Hemos de destacar en este aspecto la disparidad de manufacturación y componentes que se pueden apreciar con el resto de cerámicas halladas en los mismos niveles arqueológicos del yacimiento, puesto que se trata de cerámicas con restos de material orgánico en sus superficies (fruto del contacto del combustible del horno con los vasos) y la gran cantidad de desgrasantes de gran tamaño y de origen calcáreo, con una orientación de los mismos totalmente anárquica.

En un segundo paso realizamos un análisis visual más pormenorizado a través de lámina delgada. Es en este método donde hemos podido apreciar una caracterización bastante más detallada en cuanto a la manufacturación de las piezas. Como ya hemos apuntado anteriormente, se apreciaba una buena orientación, que se observa mediante el microscopio con mucho mayor detalle, y que se desarrolla claramente paralela a las paredes de los vasos en sentido longitudinal.

Otro elemento observable mediante esta técnica es la existencia de halos de presión. Se trata de unos círculos que se forman en torno a los minerales más duros por la presión de la matriz arcillosa sobre los mismos. Este hecho nos denota claramente su manu- 
PLAGIOCL MAGLEMIT DOLOMITA

PLAGIOCL

MAGLEMIT

DOLOMITA

, 44062

, 49632
, 41596

Extraction 1 for analysis 1, Principal Components Analysis (PC)

Initial statistics:

$\begin{array}{lrrrrrr}\text { Variable } & \text { Communality } & * & \text { Factor } & \text { Eigenvalue } & \text { Pct of var } & \text { Cum Pct } \\ \text { FIIISIII } & 1,00000 & \star & 1 & 3,13240 & 39,2 & 39,2 \\ \text { CALCITA } & 1,00000 & \star & 2 & 2,25652 & 28,2 & 67,4 \\ \text { CUARZO } & 1,00000 & \star & 3 & 1,05936 & 13,2 & 80,6 \\ \text { HEMATITE } & 1,00000 & \star & 4 & , 83209 & 10,4 & 91,0 \\ \text { FELDESPA } & 1,00000 & \star & 5 & , 47128 & 5,9 & 96,9 \\ \text { PLAGIOCL } & 1,00000 & \star & 6 & , 14264 & 1,8 & 98,7 \\ \text { MAGLEMIT } & 1,00000 & * & 7 & , 10498 & 1,3 & 100,0 \\ \text { DOLOMITA } & 1,00000 & \star & 8 & , 00073 & , 0 & 100,0\end{array}$

PC extracted 3 factors.

Factor Matrix:

$\begin{array}{lrrr} & \text { Factor } 1 & \text { Factor } 2 & \text { Factor } \\ \text { DOIOMITA } & , 89027 & -, 04747 & -, 35217 \\ \text { CALCITA } & , 82413 & -, 19884 & -, 32213 \\ \text { FIIISILI } & -, 71042 & -, 68210 & -, 07699 \\ \text { HEMATITE } & -, 64690 & , 32196 & -, 31429 \\ \text { FELDESPA } & -, 55590 & , 75893 & , 01720 \\ \text { MAGLEMIT } & , 05551 & , 68873 & , 18099 \\ \text { CUARZO } & , 60184 & , 67616 & , 19433 \\ \text { PLAGIOCL } & , 25131 & -, 37187 & , 80997\end{array}$

$\rightarrow$ EACTOR

$\rightarrow$ /VARIABLES filisili calcita cuarzo hematite feldespa plagiocl maglemit

$\rightarrow$ dolomita /MISSING IISTWISE /ANALYSIS filisili calcita cuarzo hematite

$\rightarrow$ feldespa plagiocl maglemit dolomita

$\rightarrow$ /PRINT INITIAL CORRELATION SIG KMO EXTRACTION ROTATION

$\rightarrow \quad$ /FORMAT SORT

$\rightarrow$ /PLOT ROTATION

$\rightarrow$ /CRITERIA MINEIGEN(1) ITERATE (25)

$\rightarrow$ /EXTRACTION PC

$\rightarrow$ /CRITERIA ITERATE (25) DELTA(0)

$\rightarrow$ /ROTATION OBLIMIN

$\rightarrow$ /SAVE REG (ALL) 
Analysis number 1 Listwise deletion of cases with missing values

Correlation Matrix:

FILISILI CALCITA CUARZO HEMATITE FELDESPA PLAGIOCL MAGLEMIT

\begin{tabular}{|c|c|c|c|c|c|c|c|}
\hline EILISILI & 1,00000 & & & & & & \\
\hline CALCITA &,- 41532 & 1,00000 & & & & & \\
\hline CUARZO &,- 92420 &, 20541 & 1,00000 & & & & \\
\hline HEMATITE &, 20364 &,- 34675 & -.30758 & 1,00000 & & & \\
\hline FELDESPA &,- 13408 &,- 65418 & 21856 &, 53029 & 1,00000 & & \\
\hline PLAGIOCL &,- 02285 &, 11358 & -.00610 &,- 31976 &,- 41255 & 1,00000 & \\
\hline MAGLEMIT &,- 45767 &, 02434 & .30547 & .20297 & 34324 &,- 05846 & 1,00000 \\
\hline DOLOMITA &,- 59316 & .80968 &, 40953 &,- 44933 &,- 50029 &,- 00361 &,- 08298 \\
\hline
\end{tabular}

DOLOMITA

DOLOMITA 1,00000

Kaiser-Meyer-olkin Measure of Sampling Adequacy $=, 18882$

Bartlett Test of Sphericity $=46,53500$, significance $=\quad, 01533$

1-tailed Significance of Correlation Matrix:

'. 'is printed for diagonal elements.

FILISILI CALCITA CUARO HEMATITE FELDESPA

FILISILI

CALCITA

CUARZO

HEMATITE

EELDESPA

PLAGIOCL

MAGLEMIT

DOLOMITA

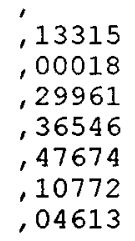

, 04613
1

, 21036

, 28605

, 49379

, 21204

, 13684
, 07096

, 20078

, 30022

, 11250
'

, 13491

, 18291

, 08509 facturación a molde rígido, para posteriormente ejecutar su acabado mediante la adición del borde hecho mediante el aplique de un churro de arcilla, para finalmente aplicar un espatulado o engobado sobre sus superficies. Este hecho resulta llamativo puesto que, si bien existen elementos de cestería que se podrían considerar como moldes cerámicos (constatado en este mismo yacimiento y algunos otros del Sureste Peninsular), los halos de presión no se detectan de igual forma que en nuestro caso, puesto que presenta- rían una orientación mucho más irregular y no estarían tan marcados.

Los porcentajes de desgrasante respecto a la matriz presentan una cierta uniformidad, a excepción de tres muestras $(5014,5001$ y 5000), para estas últimas la cantidad de desgrasante llega a un $15 \%$, mientras que el resto representa un porcentaje entre el $5 \mathrm{y}$ el $6 \%$. Los desgrasantes son mayoritariamente, junto a la antes mencionada obsidiana, moscovita, óxidos de hierro y cuarzo, y en mucha menor proporción bio- 


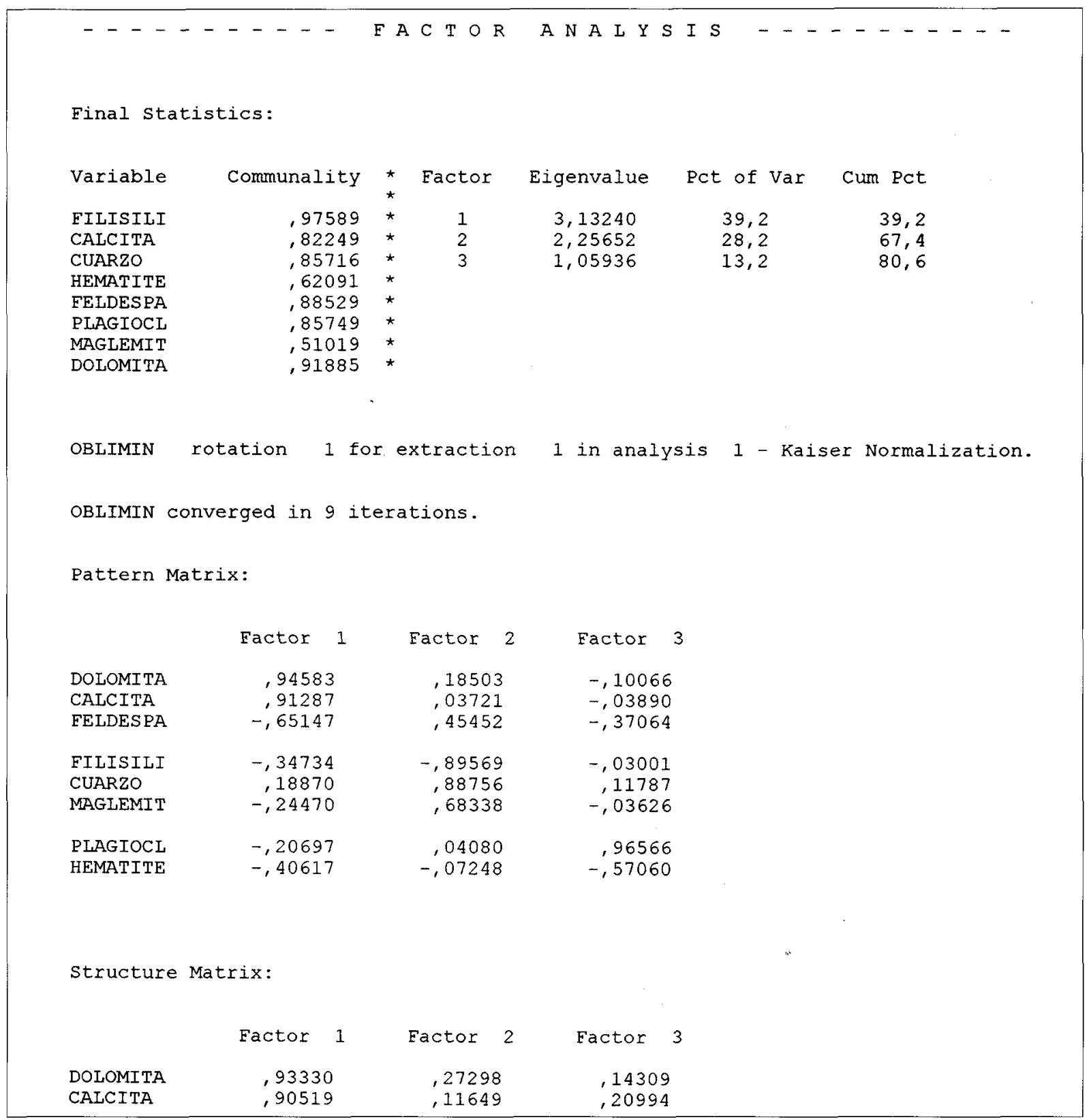

tita, zircón, feldespatos y en dos muestras (50025004) andalucita. Los minerales mayoritariamente son originarios de rocas metamórficas. La moscovita, biotita y andalucita y el zircón pueden tener origen ígneo, pero pueden acompañar a las filitas de origen metamórfico. Los feldespatos pueden tener un origen ígneo o volcánico, al igual que la obsidiana detectada como desgrasante pero aparecen poco representados (únicamente muestras 5022 y 5000 ) por lo que podrían ser de una zona donde ambas geologías se localizarían.

Por lo tanto, tenemos una mezcla de materiales con claro origen metamórfico en la mayoría de los casos, junto con minerales de origen ígneo y/o volcánico. Si bien existen puntos de referencia con afloramientos metamórficos a lo largo de todo el Sureste de la Península Ibérica (Murcia y Almería), son más escasas las zonas con vulcanismo reciente (Campo de 


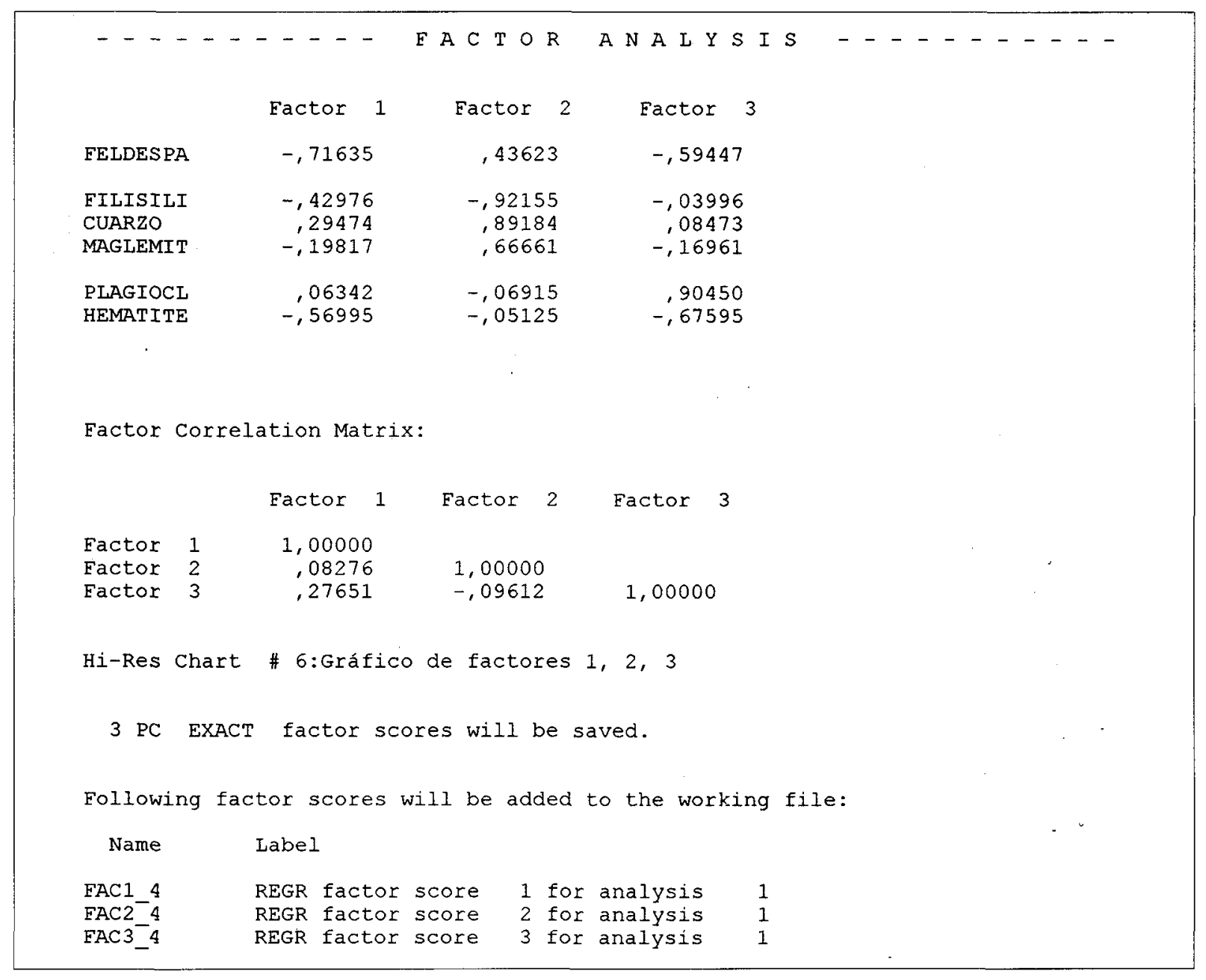

Calatrava, Ciudad Real), zonas que además se encuentran bastante alejadas de nuestro yacimiento, toda vez que los afloramientos volcánicos no se ubican junto a metamórficos en esta zona, sólo en el Cabo de Gata podemos apreciar material ígneo junto a metamórfico. Todo ello nos hace pensar en una clara procedencia alóctona para estas cerámicas.

Otro factor a tener en cuenta es la clara diferenciación con el resto de cerámicas de los mismos niveles. Como hemos apuntado antes, los desgrasantes se disponen de manera anárquica, no se aprecian halos de presión, los tratamientos superficiales son de peor calidad y los minerales aparecidos, en mayor o menor proporción respecto a la matriz arcillosa, difieren de los mencionados anteriormente, son más propios de rocas sedimentarias con abundantes calcitas, cuarzo y carbonatos, en los cuales se pueden lle- gar a distinguir globigerinas, algas rodofíceas, equínidos y ostreidos, fósiles estos relacionados con margas y carbonatos del Eoceno, formación muy abundante en las cercanías de nuestro yacimiento. Otro elemento diferenciador es la utilización de chamota como desgrasante en todas las cerámicas de composición calcárea de los mismos niveles, chamota que a su vez también está compuesta por cuarzos (algunos de ellos triásicos) y calcita.

Por todo ello, estamos ante producciones distintas, con una manufacturación y composición mineral diferente entre las cerámicas rojas y el resto de vasos aparecidos en nuestro yacimiento.

Tras estas primeras apreciaciones, sometimos las muestras a difracción de Rayos X (XRD), dándonos distintos resultados en las proporciones de los compuestos, e incluso en algunos casos diferencias de composiciones. 


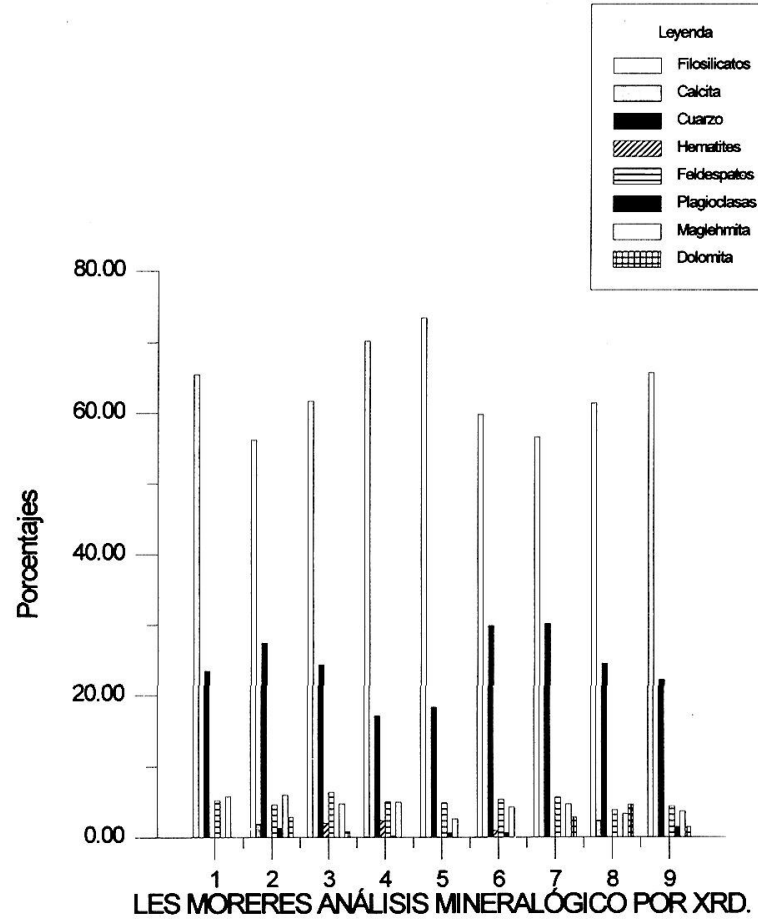

Fig. 1 .- Gráficas de composición mineralógica por difracción de Rayos X.

\section{Análisis en Componentes Principales} (Rotación Oblimin)

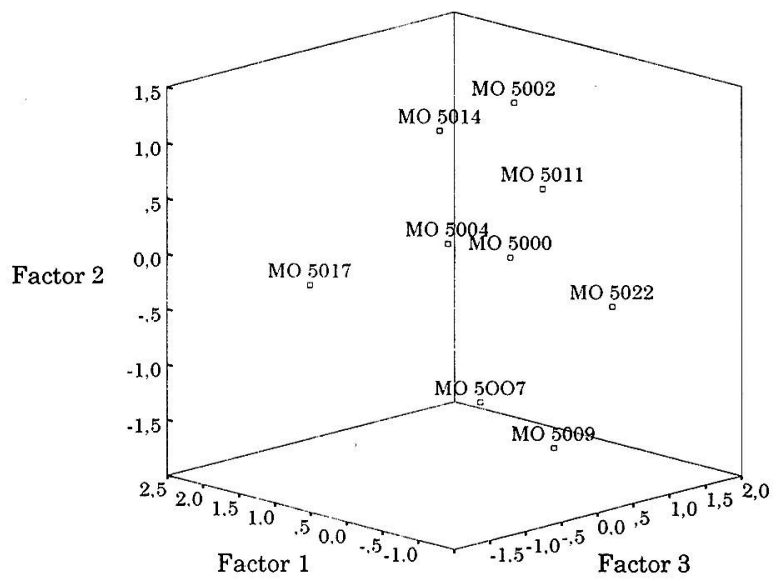

Fig 2 - Gráficas de composición mineralógica por difracción.
Análisis en Componentes Principales

(Rotación Oblimin)

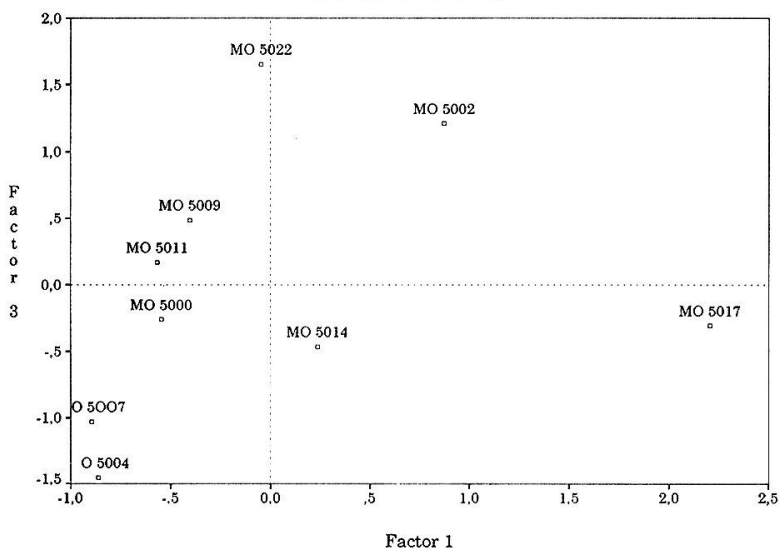

Análisis en Componentes Principales

(Rotación Oblimin)

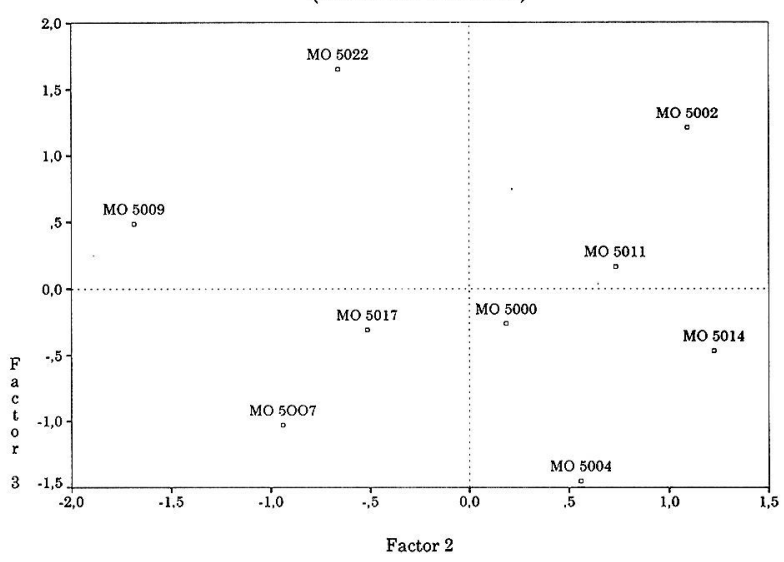

Fig. 3.- Difractogramas de las muestras analizadas.

Análisis en Componentes Principales

(Rotación Oblimin)

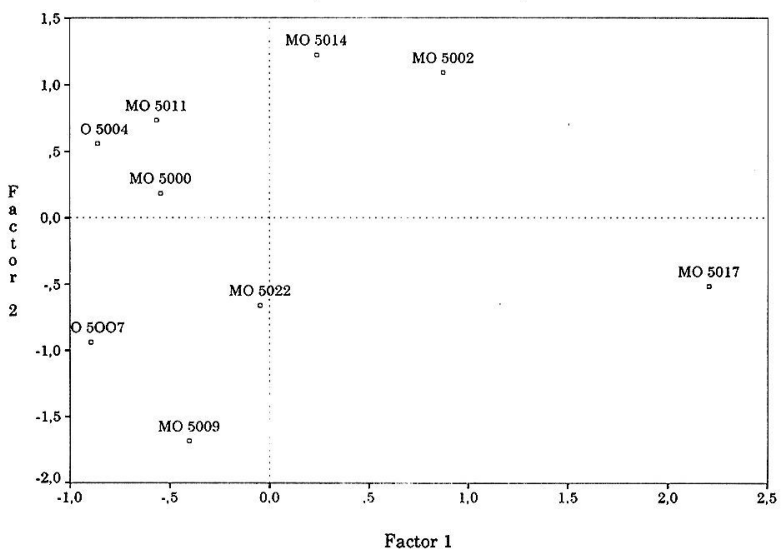

Fig. 4.-Difractograma de la muestra 5022. 


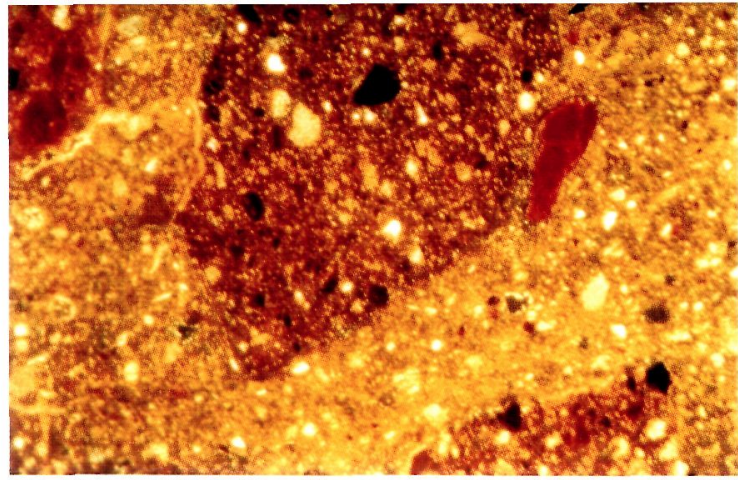
$ـ^{1 \mathrm{~mm}}$

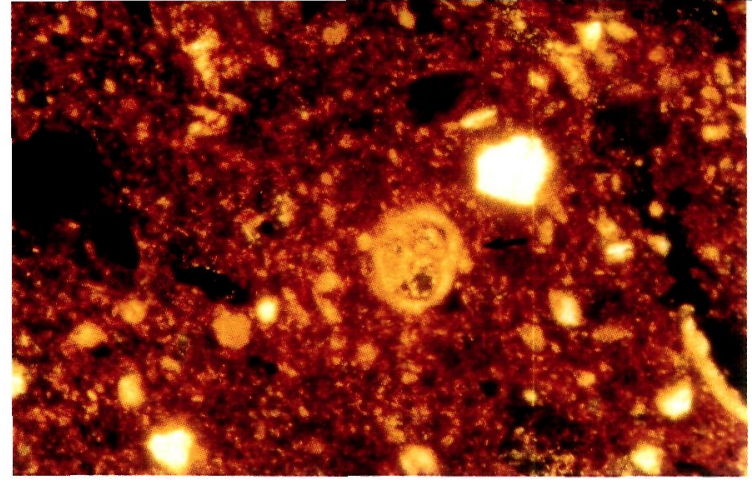

$\longleftarrow^{1 \mathrm{~mm}}$

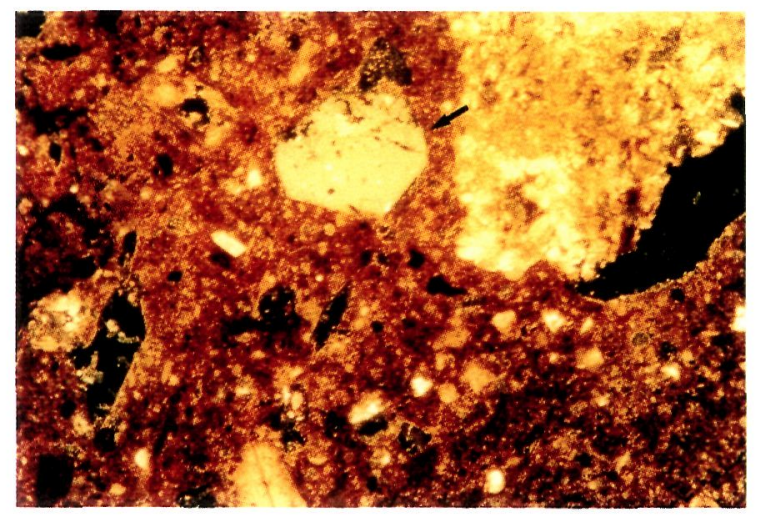

$1 \mathrm{~mm}$

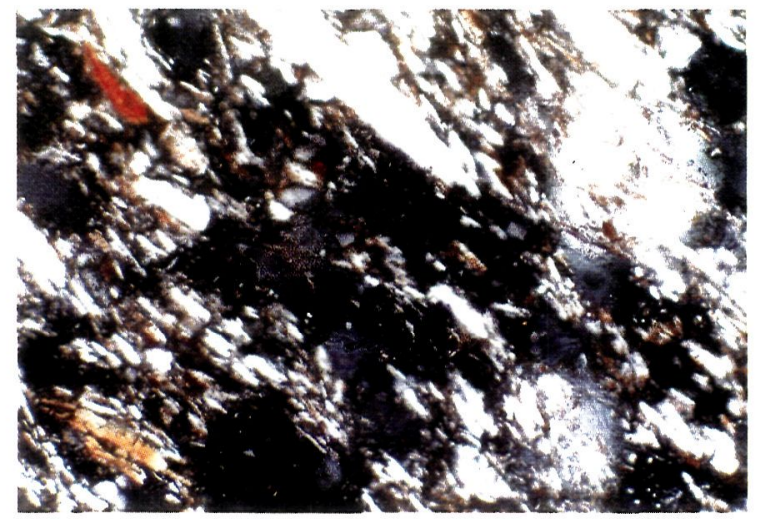

$1^{\mathrm{mm}}$

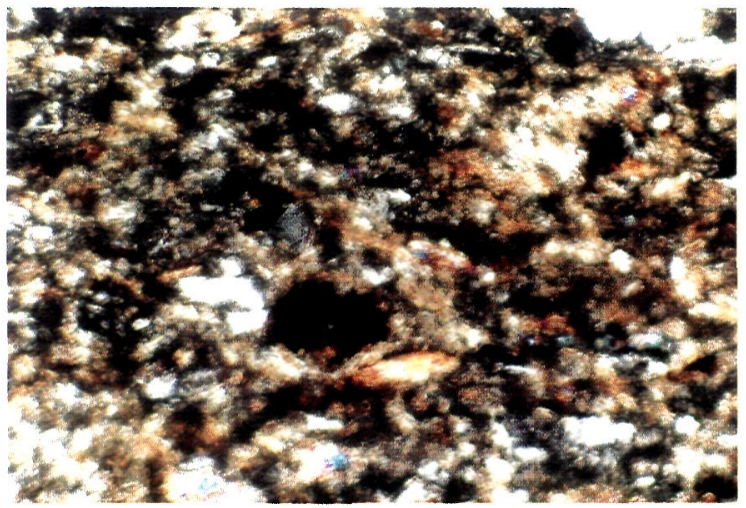
$\underbrace{1 \mathrm{~mm}}$

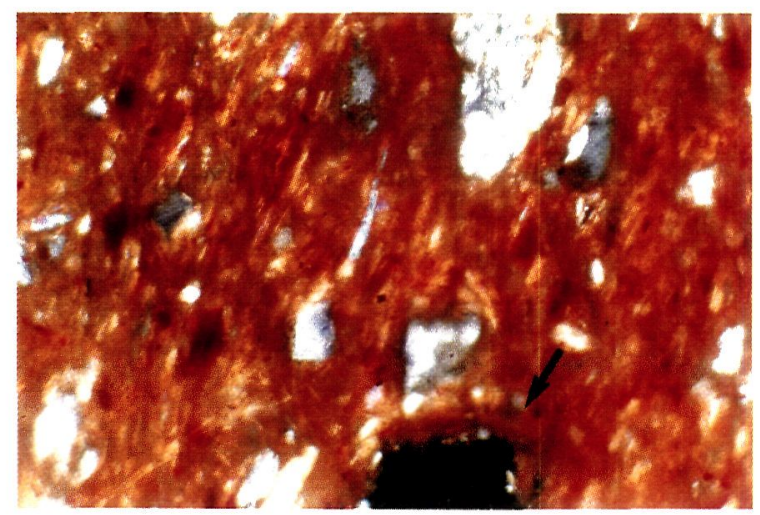

$1 \mathrm{~mm}$

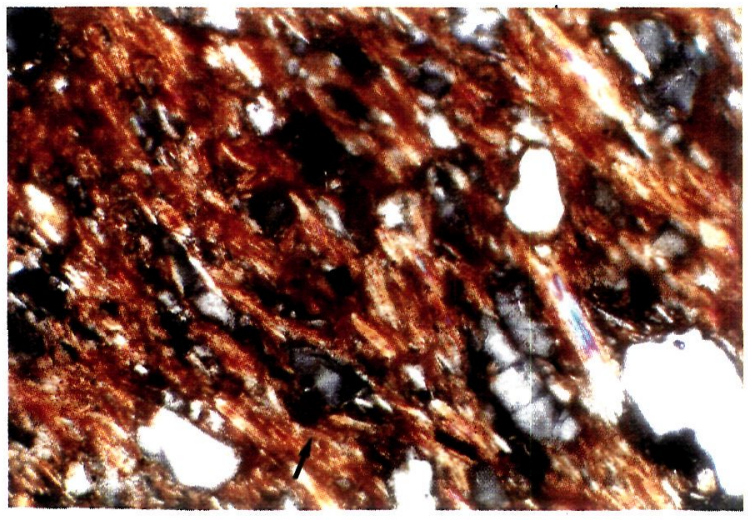

$1 \mathrm{~mm}$

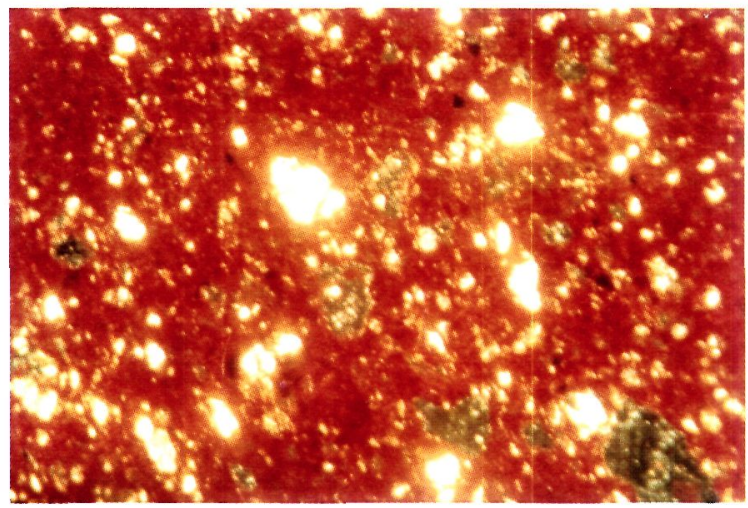

$\mathrm{I}^{1 \mathrm{~mm}}$

Lámina 1.- 1. Chamota en cerámicas con carbonatos y cuarzos. 2. Globigerina del Eoceno en cerámicas con carbonatos. 3. Carbonatos y cuarzo del Trías, materiales cercanos al yacimiento. 4. Orientación en los minerales de las cerámicas rojas de Les Moreres. 5. Cuarzo esquistos y micas donde se desarrollan los halos de presión. 6 y 7. Matriz orientada, donde también se puede apreciar biotita, moscovita, cuarzo metamórfico y óxidos de hierro con halos de presión. 8. Minerales desorientados de la zona del borde de las cerámicas rojas. 


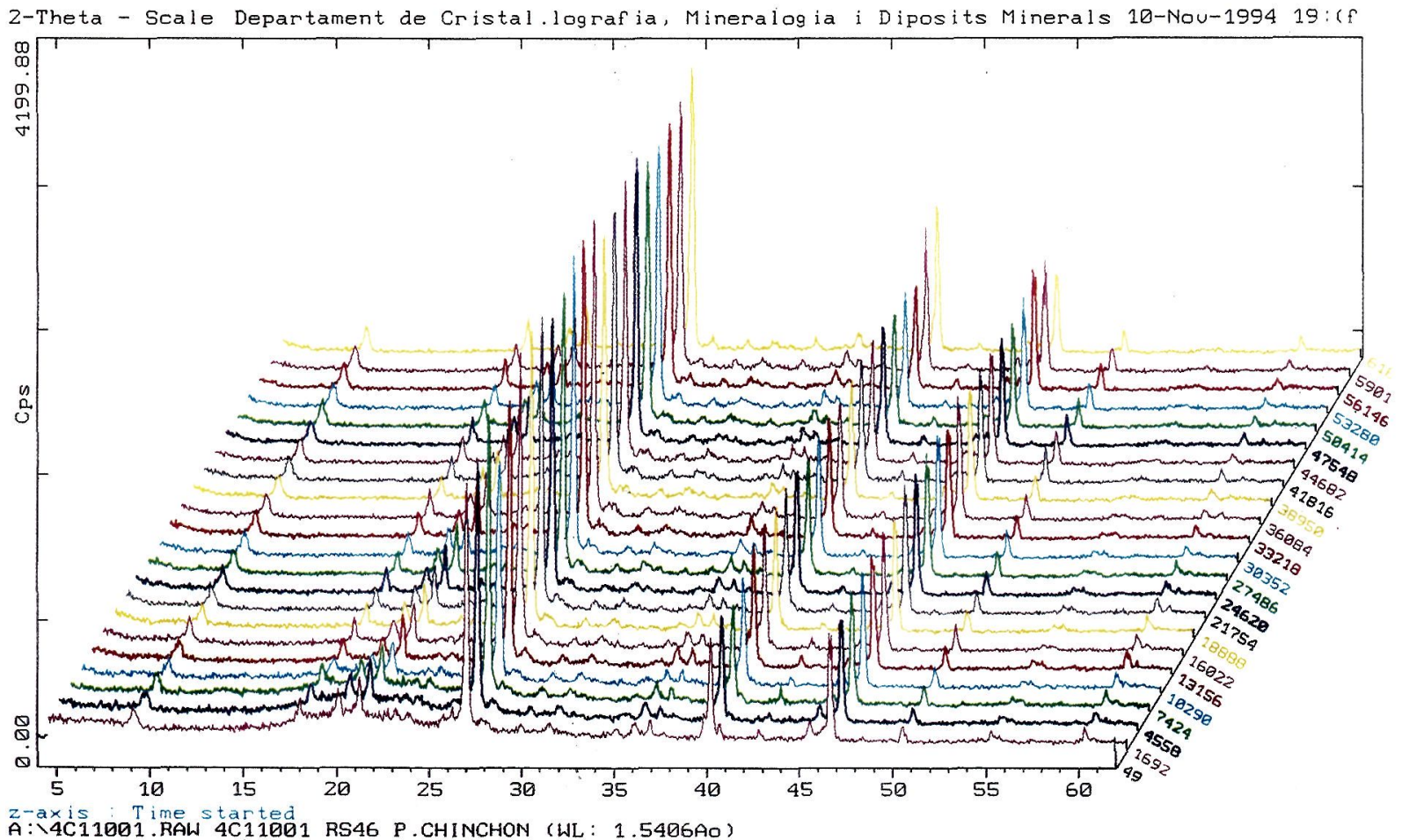

Fig. 5.- Difractograma de incrementos de temperatura de un fragmento de cerámica monocroma roja con sus cambios de fase.

Como se puede apreciar en la tabla de datos, existen diferencias en cuanto a componentes, si bien debemos de tener en cuenta que en la difracción de Rayos X aparecen los compuestos más cristalinos y en cantidades suficientes para su detección. Como se puede observar en las gráficas, se advierte una cierta disparidad en los componentes cristalinos de las cerámicas a excepción de los principales.

Los resultados obtenidos hacen pensar en grupos diferentes, atendiendo lógicamente al pequeño número de muestras que no permite un balance exhaustivo estadístico. Con todo, hemos tratado de observar el agrupamiento de las mismas por medio del análisis de componentes de los escasos fragmentos cerámicos constatados hasta el momento y aplicando el análisis multivariante.

Como se puede apreciar existe un agrupamiento de componentes principales y una dispersión de algunos compuestos secundarios, en unos casos como consecuencia de neoformaciones por altas temperaturas (caso de la aparición de hematites, a partir de $800^{\circ} \mathrm{C}$ ), y en otros por existir unos componentes que posiblemente estarían representados en la materia prima de origen como son los feldespatos y plagioclasas que pueden tener un origen ígneo o volcánico, coincidien- do la aparición de un fragmento de obsidiana con la muestra 5022. Todo ello podría tener sentido al ser el yacimiento de arcillas un lugar con formaciones volcánico-ígneas, junto a zonas metamórficas.

Incidiendo en el tema de las temperaturas de cocción y dados los materiales de composición de las cerámicas (no aparecen carbonatos ni calcita, por lo que se hace más difícil detectar fases de alta temperatura), no obstante, hemos realizado un múltiple análisis de Difracción de Rayos X, con incrementos de temperatura en amplitudes térmicas de $20{ }^{\circ} \mathrm{C}$ a partir de temperatura ambiente y de $500{ }^{\circ} \mathrm{C}$ hasta $900{ }^{\circ} \mathrm{C}$, pudiendo asegurar la temperatura de cocción de los vasos cerámicos.

Como se puede apreciar en el difractograma (fig. 5), y según las fases minerales que aparecen, la temperatura que alcanzaron algunas de estas cerámicas estaría comprendida entre los 840 y $880^{\circ} \mathrm{C}$, temperaturas más altas de las habituales para los vasos de esta época, que estarían comprendidas entre los $650^{\circ}$ y $770^{\circ} \mathrm{C}$.

Por lo tanto, se puede observar una clara diferenciación entre las cerámicas que podemos calificar como comunes y las monocromas rojas en cuanto a las temperaturas alcanzadas, reafirmando, al igual que la 


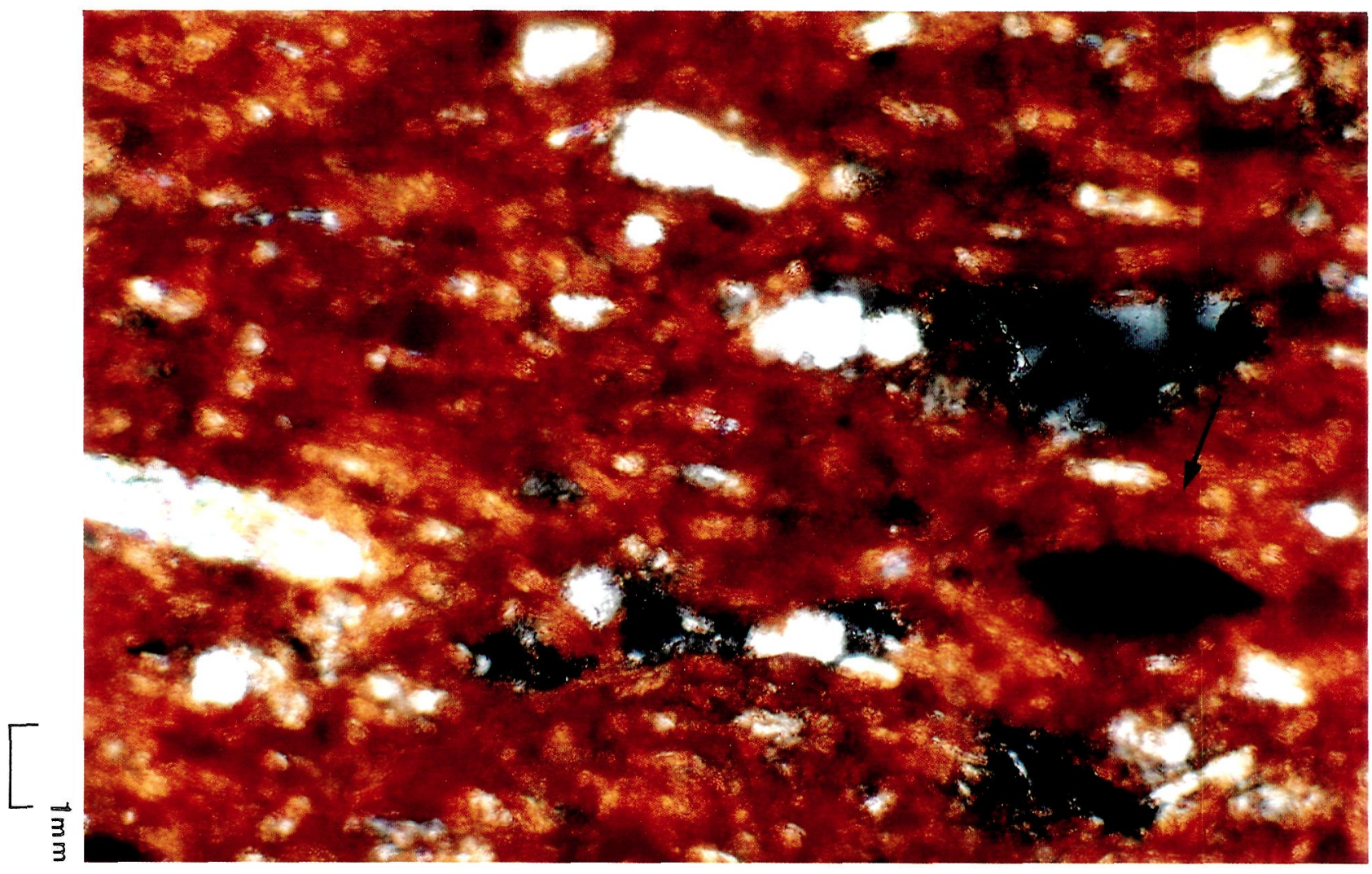

Lámina II.- Orientación de la matriz, desarrollo de halos y cristalinidad de moscovita con óxido de hierro.

elaboración, su cochura en un horno complejo donde se controlaba la temperatura y entrada de aire, pudiendo alcanzar valores más altos.

En contraposición a este tipo de cerámicas, nos encontramos con vasos con muchos elementos calcáreos (carbonatos y calcita), que en algunos casos presentan contenidos de esmectita y que se diferencian claramente del grupo anterior.

\section{CONCLUSIONES}

Por los resultados obtenidos parece ser que estamos ante un grupo de cerámicas muy distinto al resto de vasos aparecidos en los mismos niveles del yacimiento de Les Moreres; por un lado son vasos hechos mediante molde rígido con labio añadido. No existe tradición anterior, según los datos actuales, del uso del molde rígido en la península Ibérica; es decir, se hace un uso por vez primera de esta forma de manufacturación, y no tendrá una continuidad duran- te más de 1000 años (bien entrado en el Bronce Final). Por lo tanto, debemos pensar, dada la tradición de las cerámicas monocromas en el Mediterráneo y su fábrica, junto con la aparición de otros artefactos claramente importados, en contactos con gentes provenientes de otros lugares que trajeron hasta este poblado unas cerámicas con un valor, al menos, lujoso.

Las composiciones mineralógicas son distintas (las rojas no tienen contenidos calcáreos, mientras que el resto sí que contienen calcita y carbonatos); de esta forma se puede distinguir un grupo claramente autóctono con cerámicas que contienen carbonatos del Eoceno, mientras que las cerámicas rojas tienen un claro origen metamórfico-ígneo-volcánico que nos advierten claramente de su origen importado, que podría ser extrapeninsular como se ha expuesto en los anteriores apartados y que trataremos de contrastar en un futuro con las cerámicas similares del Sureste y con los análisis de elementos minoritarios de la obsidiana detectada. 
Dentro del conjunto de cerámicas rojas, y por su composición, se pueden detectar al menos tres grupos: en uno aparecen además de los compuestos comunes (moscovita, ilita y cuarzo), otros como feldespatos (de origen ígneo) y otros relacionados con fases de alta temperatura (hematites). Un segundo grupo contiene los elementos principales (ilita, moscovita y cuarzo), y un tercero en el que además de los mayoritarios se detectan plagioclasas también de origen ígneo o volcánico y en uno de los casos obsidiana, por lo que quizá deberíamos plantearnos la existencia de diferentes «fábricas» dentro de una misma zona de origen para estas cerámicas.

Sus temperaturas de cocción, en algunos casos pasarían los $840{ }^{\circ} \mathrm{C}$, algo que no es de extrañar puesto que en esta época ya se tiene un dominio de estas técnicas (aparición de hornos de tiro invertido), al menos para las culturas del sur de la Península Ibérica y de todo el Mediterráneo entre mediados y finales del III milenio a.C.

Finalmente cabe añadir que la utilización de estas cerámicas debió de ser particular, puesto que mayoritariamente no se encuentran huellas de uso de cocina ni de limpieza, lo que unido a su baja porosidad nos pondría en la pista de considerarlos vasos con carácter especial.

\section{BIBLIOGRAFIA}

ANTON BERTET, G., 1973: Análisis por difracción de Rayos $X$ de cerámicas ibérica valencianas. Serie T.V. SIP. n. ${ }^{\circ} 45$. Valencia.

ARRIBAS, A., et al., 1978: «El poblado de la Edad del Cobre de 'El Malagón' (Cullar-Baza, Granada). Campaña 1975». C.P.U.G. 3 Granada. (67-116).

BROWN, G., 1961: The X-Ray identification and cristal structures of clay minerals. London.

BUKO, A., 1984: «Problems and research prospects in the determination of the provenance of pottery». World Archaeology Vol. 15 n. $^{\circ}$ 3. Boston (348-365).
CAPEL, J. et al. 1985: «High Temperature Reactions and Use of Bronze Age Pottery from La Mancha, Central Spain». Miner. Petrogr Acta. Vol. 29. (563-575).

CAPEL MARTÍNEZ, J. 1986: «Estudio mineralógico y geoquímico de sedimentos y cerámicas arqueológicas de algunos yacimientos de La Mancha». Oretum II. Ciudad Real (55-153).

COLL, J., 1990: «El horno ibérico de Alcalá de Júcar. Reflexiones sobre los orígenes de la cocción cerámica en hornos de tiro directo y doble cámara en la Península Ibérica». Tecnología de la cocción cerámica desde la Antigüedad a nuestros días. Asociación Ceramológica. Agost (51-64).

ECHALLIER, J.C., 1984: Élements de Technologie céramique et d'analyse des terres cuites archéologiques. Documents d'Archéologie Méridionales. Serie Méthodes et Techniques 3. Lambesc (France).

LINARES, J. et al., 1983: La arcilla como material cerámico. Características y comportamiento. C.P.U.G. 8. Granada (479490):

GALLART MARTI, M.D. y LOPEZ AGUAYO, F., 1988: «Análisis mineralógico de las cerámicas neolíticas de la cueva de Chaves (Casbas, Huesca)». Bolskan. 7 Huesca (5-38).

JUAN, L.C., 1990: «Alfares y hornos de la antigüedad en la Península lbérica». Tecnología de la cocción cerámica desde la Antiguedad a nuestros días. Asociación ceramológica. Alicante (65-86).

MIDDLETON, A.P. et al., 1985: «Textural analisis of ceramic in thin sections: evaluation of grain sampling procedures». Archaeometry 27-1. Oxford (64-74)

NAVARRETE, M.S. et al. 1980: «Algunas consideraciones sobre la cerámica a la almagra del Neolítico Andaluz». C.P.U.G. 5. Granada (15-34).

NAVARRETE, M.S. et al., 1991: Ceránicas Neolíticas de la Provincia de Granada. Granada.

PAÇO, A., 1957: «Castro de Vila Nova de Sao Pedro, IX-forno de cozer cerámica». Rev. Guimaraes 67. Guimaraes (83-94).

RENFEW, C. et al., 1966: «Obsidian and Early Cultural Contact in the Near East». Bull. Prehistoric Society n. ${ }^{\circ}$ 2. (30-57).

SKIBO, M., 1992: Pottery Function. A Use-Alteration Perspective. New York.

V.V.AA., 1958: Mapa geológico de España y Portugal. Madrid.

V.V.AA., 1977: The Macdonald Encyclopedia of Rocks \& Minerals. London.

WAHL, F., 1965: «High-Temperature phases of three-layer clay minerals and their interactions with common ceramic materials». Ceramic Bulletin. Vol. 44 n.» 9. Chicago (676-681). 